NBER WORKING PAPER SERIES

\title{
THE COSTS OF AND NET RETURNS TO COLLEGE MAJOR
}

\author{
Joseph G. Altonji \\ Seth D. Zimmerman \\ Working Paper 23029 \\ http://www.nber.org/papers/w23029
NATIONAL BUREAU OF ECONOMIC RESEARCH
1050 Massachusetts Avenue
Cambridge, MA 02138
January 2017

We thank Ling Zhong, Justin Young, Stephen Lamb, and Melody Haxton for outstanding research assistance. We thank Dale Bradley and the staff of the Florida Board of Governors for help accessing cost records, and Caroline Hoxby, Kevin Stange, and participants at the NBER Productivity in Higher Education conference for valuable comments. We also thank Jamie Champion, Nancy Copa, and Tammy Duncan at the Florida Department of Education Data Warehouse for helping us access student data extracts. All errors are our own. The views expressed herein are those of the authors and do not necessarily reflect the views of the National Bureau of Economic Research.

NBER working papers are circulated for discussion and comment purposes. They have not been peer-reviewed or been subject to the review by the NBER Board of Directors that accompanies official NBER publications.

(C) 2017 by Joseph G. Altonji and Seth D. Zimmerman. All rights reserved. Short sections of text, not to exceed two paragraphs, may be quoted without explicit permission provided that full credit, including $(\subset$ notice, is given to the source. 
The Costs of and Net Returns to College Major

Joseph G. Altonji and Seth D. Zimmerman

NBER Working Paper No. 23029

January 2017

JEL No. I23,I26,J24

\begin{abstract}
This paper uses administrative student and expenditure data from Florida public universities to describe a) how the cost of producing graduates varies by major, b) how the inclusion of majorspecific instructional costs alters the estimated net returns to different fields of study, and c) how major-specific instructional expenditures changed between 1999 and 2013. We find that the cost of producing graduates in the highest cost major (engineering) is roughly double that of producing graduates in low-cost majors, such as business. Cross-major comparisons of per graduate earnings returns net of costs differ from comparisons based on earnings outcomes alone in economically significant ways for a number of fields. Differences between net returns and earnings returns per dollar of instructional spending are even more pronounced. Our analysis of trends in instructional expenditures shows that per credit expenditures for undergraduate classes dropped by $16 \%$ in Florida universities between 1999 and 2013. The largest drops occurred in engineering and health, where per credit spending fell by more than $40 \%$. Observed spending changes have little relationship with per credit costs or earnings outcomes.
\end{abstract}

Joseph G. Altonji

Department of Economics

Yale University

Box 208264

New Haven, CT 06520-8264

and NBER

joseph.altonji@yale.edu

Seth D. Zimmerman

Booth School of Business

University of Chicago

5807 S. Woodlawn Avenue

Chicago, IL 60637

and NBER

seth.zimmerman@chicagobooth.edu 


\section{Introduction}

Both casual observation and detailed survey data indicate that post-college earnings for graduates vary widely by field of study. Though this is in part driven by differences in the mix of students majoring in different subjects, both regression studies that control in detail for student background and studies relying on quasi-experimental variation in student assignment to different majors indicate that major choice plays a causal role in earnings determination (Altonji, Blom, and Meghir 2012; Altonji, Arcidiacono, and Maurel 2016; Hastings, Neilson, and Zimmerman 2013; Kirkeboen, Leuven, and Mogstad 2016). State and national policymakers observing cross-field wage differentials have proposed policies encouraging students to pursue degrees in perceived high-return areas such as the STEM fields while suggesting that students think carefully before pursuing degree programs in liberal arts with perceived low returns (Alvarez 2012; Jaschik 2014). The idea is that by choosing higher-earning degree programs, students will help raise the return on public and private investments in higher education.

While policy discussions tend to focus on labor market outcomes, pecuniary returns on educational investments depend on costs as well as future earnings. At least until recently, tuition costs have not varied across fields, or have not varied much (CHERI 2012; Ehrenberg 2012; Stange 2015). However, the available evidence suggests that the costs of producing graduates or credit hours varies substantially by field (Johnson 2009; Conger et al. 2010). Some majors may lead to high earnings but be costly to produce, offering lower net returns per graduate or per invested dollar than lower-earning but less costly majors. An understanding of net private returns (private returns net of instructional costs) may be valuable for policymakers seeking to maximize the efficacy of higher education spending.

This paper brings together evidence on major-specific earnings outcomes and production costs to provide what is to the best of our knowledge the first assessment of the net returns to college major. We evaluate earnings outcomes using two data sources: administrative records of educational and early career labor market outcomes for a large sample of in-state, first-time-in-college students enrolling in the Florida State University System (SUS), and nationally representative data from the American Community Survey (ACS). Though we lack experimental or quasi-random variation in the assignment of students to college major, the Florida data do contain a detailed set of control variables, including high school grades and college admissions test scores. We evaluate the costs of producing graduates and credits in different fields using publicly available administrative expenditure reports from the SUS Board of Governors (FLBOG). These reports detail total and per credit direct and indirect instructional expenditures within institutionmajor-course level cells. Majors are defined by two-digit CIP codes. We link the expenditure reports to microdata on student course-taking to compute total instructional expenditures over college careers for the same graduates and dropouts for whom we observe earnings outcomes.

We use these data to construct two measures of net returns. The first is the present discounted value (PDV) 
of net earnings returns per graduate by major. These values are potentially relevant for a university or policymaker trying to decide whether to open an additional spot in one major versus another. The second measure is the PDV of net returns per dollar of incurred cost. This is potentially relevant for universities or policymakers with a fixed budget trying to decide which major or majors to expand.

We find that costs per credit and per graduate vary by field, and that measures of earnings returns net of cost are in many cases significantly different from returns measured using labor market outcomes only. Engineering majors are the most expensive, with total costs of $\$ 62,297$. This compares to a graduate weighted median degree cost of $\$ 36,369$ across all majors and a cost of $\$ 31,482$ for business, the second cheapest major. The graduate-weighted standard deviation of the distribution of the PDV of costs by major is $\$ 7,187$ (in 2014 USD). This is roughly one quarter the size of the standard deviation of the PDV of the earnings effects through age 32, the oldest age at which we observe earnings in the Florida data, and $13.5 \%$ of a standard deviation of the PDV of earnings effects if we extrapolate those effects out to age 45. ${ }^{1}$ Measuring returns on a per graduate basis, we find that low-cost but relatively high-earning fields like business and computer science offer higher net returns through age 32 than higher-earning but higher-cost majors like engineering. On the whole, however, differences in per graduate net returns across degree programs are driven primarily by differences in earnings. The correlation between per graduate PDVs of earnings net of costs through age 32 and estimates of log earnings effects is 0.95 . The role of earnings differences in driving PDVs is even larger when we consider earnings through age 45.

Differences between net returns and earnings returns are more striking when evaluated per dollar of instructional expenditure. High earning but high cost degree programs in engineering and health offer per dollar returns that are similar to lower earning but lower cost programs in fields like education and philosophy. High earning but low cost degree programs in fields like business and computer science have the highest net returns by this measure. The graduate-weighted correlation between per dollar estimates of net PDVs through age 32 and estimates of log earnings effects is 0.52 .

The last component of our empirical work considers trends in field-specific per credit expenditures over the 1999-2013 period. On average, per credit expenditures dropped by 16\% in the Florida SUS over this period. Rates of decline differ by field. The largest drops occured in engineering and health, growing fields with high per graduate returns. Per credit funding in these fields fell by more than $40 \%$ over the period. Overall, costs per credit fell more in fields with large increases in credit hours. The changes have little relationship with average per credit costs or with earnings effects. Our findings suggest that long-run declines in funding at the institution level affect fields differentially. This may alter the distribution of degree types in addition to reducing overall completion rates, as reported in Bound and Turner (2007) and Bound, Lovenheim, and Turner (2010). An analysis of staffing data for the University of Florida suggests that changes in faculty and staff inputs per credit can explain about half of the overall decline. Faculty

\footnotetext{
${ }^{1}$ The ratio does not account for sampling error in the earnings effects estimates, which is substantial in the case of the estimates based the Florida administrative data. We find similar results using ACS data.
} 
FTEs per credit declined 16\% between 2000 and 2012.

The paper proceeds as follows. In Section 2 we discuss our contribution to existing work on the topic. In Section 3 we present a model of the tradeoffs facing policymakers deciding how to allocate program spots and funding across majors. In Section 4 we describe our data. Sections 5 and 6 present our findings, and Section 7 concludes.

\section{Related literature}

Our work builds on two strands of literature. The first is the rapidly growing literature on the return to education by field of study, surveyed by Altonji, Blom, and Meghir (2012; henceforth ABM) and Altonji, Arcidiacono, and Maurel (2016; henceforth AAM). A core challenge in this literature is to understand how the process by which students choose different fields affects observed earnings outcomes. A small set of studies, including Arcidiacono (2004) and Beffy et al. (2012), use structural models of field choice and wages to address this issue. A few other studies use plausibly exogenous variation in access to fields of study to identify returns. Hastings, Neilson, and Zimmerman (2013; henceforth HNZ) and Kirkeboen, Leuven, and Mogstad (2016; henceforth KLM) use the fact that Chile and Norway (respectively) determine admission to particular school/field of study combinations using an index of test scores and grades. This admissions structure provides the basis for a fuzzy regression discontinuity design. Findings from these studies indicate that admission to different fields of study can have large effects on earnings outcomes.

In the absence of quasi-experimental variation, we follow the vast majority of studies that use multivariate regression with controls for student characteristics. ${ }^{2}$ While omitted variables bias is a concern, we do have access to high school transcript information and test scores. Consequently, our control set is richer than that of most previous studies. We find large differences in the returns across majors that follow the general pattern in previous studies (see ABM and AAM). Using the earnings regressions, we compute the present discounted value of earnings by field, taking the education major as the omitted category. As we discuss in Section 4, we have some concerns about earnings outcomes measured using our Florida data because a) the data cover early career outcomes only, and b) we do not observe earnings outcomes for students who leave Florida. We therefore use the ACS to construct alternate measures of earnings effects. These are very similar to estimates described in ABM, with the key differences being that we create more aggregated major categories to correspond with what we observe in the Florida administrative records and that we use annual earnings rather than hourly wage rates as our earnings measure.

We also contribute to a much smaller literature on education production costs. Bound and Turner (2007)

\footnotetext{
${ }^{2}$ Examples include Berger (1988), Chevalier (2011), Grogger and Eide (1995), Webber (2014), and Hamermesh and Donald (2008).
} 
and Bound, Lovenheim, and Turner (2010) show that reductions in per-student resources have played an important role in the decline in rates of college graduation since the 1970s. In research focusing on cost heterogeneity by major, Middaugh et al. (2003), Johnson (2009; 2013), and Conger et al. (2010) provide evidence that instructional costs vary across fields, and tend to be higher for STEM courses, as well as courses in instruction-intensive non-STEM fields like education, art, and nursing (Middaugh et al. 2003). Thomas (2015) uses data on course selection and instructor costs for particular courses at the University of Central Arkansas to estimate a model of how universities decide what courses to offer. Our cost-side analysis most closely parallels Johnson (2009), who also uses data on expenditures and course-taking from the Florida State University System. Our findings on the average and major-specific per credit and per graduate costs are similar to his. Though our research focuses exclusively on Florida, evidence on costs from Ohio, New York, and Illinois suggests that other states exhibit similar patterns of expenditure across field and trends over time (Conger et al. 2010).

Our main contributions are to a) highlight the importance of considering costs as well as earnings when evaluating the efficacy of field-specific educational investments, and b) bring earnings and cost estimates together to produce what to our knowledge are the first available measures of per-person and per-dollar net returns. We interpret our findings cautiously. Our estimates of earnings effects may be biased. Our measures of costs are based on average expenditures which may diverge from the marginal cost concepts that should guide institutional decision-making. Still, we believe our results represent a jumping-off point for future research into universities' production functions.

We also provide new evidence on heterogeneity in major-specific spending trends. Much previous work on major-specific spending has focused on snapshots of spending for particular cohorts of graduates. One exception, Conger et al. (2010), documents trends in major-specific spending in the SUS system over the 2002-2007 period, when both our data and theirs show little change in per credit spending. Using a longer time window, we document a secular decrease in spending, with timing that coincides with economic downturns in 2001 and 2008.

\section{Private Incentives, Externalities, and Choice of Major}

In this section we motivate our focus on instructional costs using a simple model of optimal major choice from the point of view of both the individual and the social planner. Our focus is on how labor market returns, instructional costs, and tuition influence choice in an environment where taxation and externalities cause the private and social values of majors to differ. We abstract from the extensive margin choice to attend college, as well as from the college completion margin.

Students choose majors to maximize utility. The utility from a given major depends on earnings returns, tuition, and the nonpecuniary benefits associated with its coursework and the occupations it leads to. 
Assuming additive separability, the utility $U_{i}^{f}$ that student $i$ receives from enrolling in major $f$ is

$$
U_{i}^{f}=u_{i}\left((1-t) Y^{f}-\tau^{f}\right)+V_{i}^{f}
$$

where $Y^{f}$ is the present discounted value of earnings for individuals who enroll in $f, t$ is the tax rate on earnings, $\tau^{f}$ is the tuition in major $f$, and $V_{i}^{f}$ is $i$ 's non-pecuniary utility from major $f$. We assume for simplicity of exposition that earnings and tuition do not vary across individuals within a major, and that tax rates are constant. We also abstract from general equilibrium effects on skill prices of large changes in the allocation of students across majors. The function $u_{i}$ captures utility from the consumption of goods and services financed out of earnings net of tuition costs. $V_{i}^{f}$ depends on preferences over subject matter and occupations, academic preparation, and ability.

Students rank fields based on their preferences, and choose the highest utility field available to them from some set of $F$ majors, perhaps given some capacity constraints. We discuss these in more detail below. Note that students consider earnings $Y^{f}$ and tuition $\tau^{f}$, but not the costs of providing major $f$.

The social planner's problem differs from the individual's problem in three respects. First, the planner values $Y^{f}$, not just the after tax component. Second, the planner considers education production costs $C^{f}$, which may vary by major. Third, the planner considers the externalities associated with graduates in different fields. The value $S U_{i}^{f}$ that the planner places on a degree in $f$ for student $i$ is

$$
\begin{aligned}
S U_{i}^{f} & =U_{i}^{f}+\lambda\left[t Y^{f}+\tau^{f}-C^{f}\right]+E X T^{f} \\
& =u_{i}\left((1-t) t Y^{f}-\tau^{f}\right)+V_{i}^{f}+\lambda\left[t Y^{f}+\tau^{f}-C^{f}\right]+E X T^{f}
\end{aligned}
$$

In the above equation $\lambda$ is the marginal utility generated by an extra dollar of goverment transfers and expenditures made possible by tax and tuition revenue. EXT $T^{f}$ is the net social externality associated with an extra graduate in field $f .^{3}$

An instructive special case is when utility is linear in consumption, so that

$$
u_{i}\left(Y^{f}(1-t)-\tau^{f}\right)=\theta_{i}\left[Y^{f}(1-t)-\tau^{f}\right]
$$

\footnotetext{
${ }^{3}$ Lange and Topel (2006), Moretti (2004), and McMahon (2009) discuss the social benefits of higher education in general. Studies such as Currie and Moretti (2003) focus on effects on political participation and citizenship, on crime, and on parenting. There is much less evidence regarding differences across fields in externalities. Much of the policy discussion of field specific externalities centers on STEM education. For a recent example, see Olson and Riordan (2012). Note that large changes in the relative supply of majors would alter $E X T^{f}$ in addition to $Y^{f}$.
} 
Assume the marginal utility of income does not vary, so that $\theta_{i}=\theta$. Since a benevolent planner would choose taxes and transfers and public expenditures so that the marginal utility generated by expenditures matched the marginal benefit of private consumption, we set $\theta=\lambda$. Then $i$ 's utility from enrolling in $f$ is

$$
U_{i}^{f}=\lambda\left[(1-t) Y^{f}-\tau^{f}\right]+V_{i}^{f}
$$

and the planner's valuation simplifies to

$$
\begin{aligned}
S U_{i}^{f} & =\lambda\left[Y_{i}^{f}-C^{f}\right]+V_{i}^{f}+E X T^{f} \\
& =U_{i}^{f}+\lambda\left(t Y^{f}+\left(\tau^{f}-C^{f}\right)\right)+E X T^{f}
\end{aligned}
$$

We make two observations based on equation 4. First, the individual's preferences will be identical to the planner's when $C^{f}-\tau^{f}=t Y^{f}+E X T^{f} / \lambda$. Left unconstrained, individuals will choose the same allocation as the planner when tuition subsidies $C^{f}-\tau^{f}$ are sufficient to a) offset the wedge between individual and planner preferences created by the tax rate, and b) account for positive or negative externalities generated by enrollment. In the first part of our empirical work, we document differences in tuition subsidy levels by field of study. Second, the planner's valuation depends on $Y^{f}-C^{f}$, i.e. earnings net of costs for enrolled students. Our empirical work presents estimates of these quantities, which would determine the planner's preferences in the absence of externalities and non-pecuniary differences across majors.

Our empirical work also considers differences in per-dollar returns to field of study. To understand why this quantity is relevant for policy, consider a case in which student and planner preferences are as above, but where students cannot sort freely across fields.

Specifically, assume that at least some fields are subsidized in the sense that $C^{f}>\tau^{f}$, and have budget limits $B^{f}$, with corresponding enrollment caps of $N^{f}=B^{f} /\left(C^{f}-\tau^{f}\right)$. Students are allocated to fields in a way that may depend on student preferences over fields and admissions' committee preferences over students.

The idea of a hard cap on major-specific enrollment corresponds closely with institutional details in many non-US countries, such as Norway and Chile (see HNZ and KLM for more details). It is a reasonable approximation of US institutions that, e.g., establish minimum GPA standards for enrollment in some majors, or where lack of available seats in required courses leads to de facto limits on enrollment.

The planner has an opportunity to expand the budget in major $f$ to allow for increased enrollment. For simplicity we assume that students who benefit from this expansion would otherwise have enrolled in a 
reference major $g$ where tuition is equal to costs and where the capacity constraint is slack. Let $D_{i f}$ be an indicator function equal to 1 if $i$ enrolls in $f$, and let

$$
S U=\sum_{i} \sum_{f} D_{i f} S U_{i}^{f}
$$

be the sum of social utility over all students. Then, the gain in social utility from a marginal increase in $B^{f}$ is given by

$$
\begin{aligned}
\frac{d S U}{d B^{f}} & =\frac{d S U}{d N^{f}} \times \frac{d N^{f}}{d B^{f}}=\frac{d S U}{d N^{f}} \times \frac{1}{C^{f}-\tau^{f}} \\
& =\frac{\lambda\left(\left(Y^{f}-C^{f}\right)-\left(Y^{g}-C^{g}\right)\right)+\left(E^{f}-E^{g}\right)+\bar{V}^{f g}}{C^{f}-\tau^{f}},
\end{aligned}
$$

where $\bar{V}^{f g}=E\left[V_{i}^{f}-V_{i}^{g} \mid i \in\right.$ marginal group]. Differences in returns net of costs are scaled by the net cost of producing majors in the destination field. We consider measures of earnings scaled by costs in section 5.5.

In practice, the social returns from marginally relaxing major-specific budget constraints will depend on the mix of majors from which students affected by the policy are drawn, and on students' relative skills in and preferences for those majors. HNZ (2013) and KLM (2016) explore these issues in detail.

\section{Data}

\subsection{Cost data}

Our cost data come from administrative expenditure reports compiled by the Board of Governors of the Florida State University System (FLBOG 2000-2014). The data span the 12 universities in the State University System. ${ }^{4}$ These are four-year public institutions that primarily offer degrees at the bachelor's level or higher. The Florida College System, which includes mostly two-year institutions, is excluded. The reports document course taking and expenditures for the state university system as a whole and within groups defined by the intersection of college major and offering institution. Majors are identified at the two-digit CIP code level. This is a relatively high level of aggregation: in 2000, there were 33 distinct major codes,

\footnotetext{
${ }^{4}$ Florida A\&M, Florida Atlantic University, Florida Gulf Coast University, Florida International University, Florida Polytechnic University, Florida State University, the New College of Florida, the University of Florida, the University of North Florida, the University of South Florida, and the University of West Florida.
} 
of which 30 reported a positive number of undergraduate student credit hours. Examples include 'Engineering' or 'English Language and Literature.' A full list is provided in Table A1. We use data obtained from academic year (AY) 1999-2000 through AY 2013-2014 versions of these reports.

Each report breaks down spending by course level and expenditure type. There are four relevant course levels for graduate and undergraduate education: lower undergraduate, upper undergraduate, masters' level courses, and doctoral courses. ${ }^{5}$ Reports describe direct expenditures for instruction, research, and public service within institution-major cells. Direct expenditures are primarily for personnel. They also compute indirect costs for activities including academic advising, academic administration, financial aid, plant maintenance, library costs, and student services. They allocate these indirect costs to institutionmajor cells based on either student credit hours (for academic advising and student services) or faculty/staff person-years (for the other listed cost types). See Johnson (2009) for a more detailed description of these data.

Table 1 describes SUS expenditures by level and type for the 2000-2001 academic year. Instructional spending totaled just over $\$ 2$ billion in that year, with direct spending accounting for $54 \%$ and indirect accounting for the rest. ${ }^{6}$ Spending on undergraduate instruction made up $72 \%$ of total instructional spending, and direct expenditures accounted for $49.7 \%$ of the undergraduate instructional total. Together, these expenditures purchased a total of over 5.7 million student credit hours, equivalent to about 190,000 student FTEs at 30 credits per year. $37 \%$ of student credit hours were at the lower undergraduate level, $49 \%$ at the upper undergraduate level, and the remainder at the graduate level. Average per credit spending was $\$ 357$, with per credit expenses increasing with course level. Non-instructional spending on research and public service added up to $\$ 483$ million.

How reliable are these cost measures? Johnson (2009) compares aggregate cost measures in the FLBOG expenditure reports to expenditure measures reported in IPEDS. The main difference between the two data sources is the FLBOG reports include only expenditures out of state appropriations and student fees. The reports do not include expenditures from other sources, like grants, contracts, or endowment income. Comparisons with IPEDS data indicate that the omission of these revenue sources may lead the expenditure reports to understate costs by $15-25 \%$. It is also worth noting that although expenditure records do include operations and maintenance, they do not include the (amortized) costs of capital investment.

Our analysis hinges on comparisons of costs across majors. Existing evidence suggests that direct expenditures consist largely of instructor salaries (Johnson 2009; Middaugh et al. 2003). They will therefore allow for meaningful cross-major comparisons to the extent that either a) faculty and other instructors allocate their time to teaching in a manner consistent with the time breakdowns they report to (or are assigned by) universities, or b) differences between reported and actual time allocations are similar across majors.

\footnotetext{
${ }^{5}$ There are also separate codes for medical school courses and clinical education for medical residents.

${ }^{6}$ All dollar values reflect 2014 USD deflated using the CPI-U except where noted.
} 
Comparisons will be uninformative if, e.g., both engineering and English professors report spending 40\% of their time on teaching and $60 \%$ as research, but in practice English professors spend $80 \%$ of their time on research and only $20 \%$ on teaching while Engineering professors stay closer to the nominal allocation. The assumptions required to believe cross-major comparisons in indirect expenditures are harder to justify. How to divide costs of building maintenance, academic advising, and similar activities across majors is not obvious. Allocating expenses based on student credit shares and faculty/staff person-year shares is an a priori reasonable strategy, but it will yield faulty comparisons if usage intensity of different resources varies by discipline.

Our analysis of per credit expenditures will focus primarily on total instructional spending at the lowerand upper-undergraduate levels. This parallels our focus on undergraduate majors in the earnings analysis. When we compute costs per graduate, we use data on all courses taken by graduating students. We focus on total as opposed to direct instructional spending because we want our cost measure to come as close as possible to capturing cost levels across majors. This choice follows Johnson (2009), who notes that this is the approach taken by the FLBOG in internal cost calculations. The tradeoff is that indirect costs may be measured less accurately. We note that direct costs are strong predictors of both indirect and total costs. In credit-weighted univariate linear regressions, direct costs explain $95.4 \%$ of the variation in total costs and $77.9 \%$ of the variation in indirect costs. Similarly, changes in direct costs explain $91.3 \%$ of changes in total costs and $60 \%$ of changes in indirect costs. In sum, we view our cost measures as reasonable though imperfect first-order approximations of the production costs of different types of college credits.

We emphasize that our cost data measure average costs, not marginal costs. The marginal cost to a university of adding an additional student in any particular major may be small if the university does not have to hire new faculty, or allocate additional funds to student programming. However, even one additional student changes expected costs by altering the probability that extra class sections will be required across the set of courses the student takes. Our estimates are likely most appropriate in the context of changes in major size or class size that are large enough to require at least some new investment in faculty and staff. Over the long run, we believe it is these types of changes that are most relevant from a policy perspective.

\subsection{Instructor Data}

We use FBLOG data on instructional personnel by field, institution, and year as part of our analysis of trends in costs and credits. The data are from the FBLOG reports discussed above. They are reported in person years and are broken out into three categories - faculty, support staff, and a combined category that includes graduate assistants, house staff, adjunct faculty, and other (hereafter, GA-AF). We have data for the University of Florida for 2000-2001 to 2012-2013. 


\subsection{Microdata extracts}

We compute earnings and total spending for graduates using aggregated extracts and regression output drawn from administrative student microdata collected by the Florida Department of Education. We have data on the population of high school graduates from 15 Florida counties over six cohorts between 1995 and 2001. There are a total of 351,198 students in this sample. These data track students from high school, through any public college or university they may attend, and into the labor market. We focus on the subset of 57,711 students who enroll in the state university system in the year following high school graduation. Labor market data come from Florida Unemployment Insurance (UI) records and include in-state labor market outcomes only. In addition to academic and labor market outcomes, these data include standard demographic variables like racial/ethnic background and free lunch status, as well as math and reading SAT scores for students who took those exams. See Zimmerman (2014) for a more detailed description.

For the purposes of this study, key academic outcomes are course-taking behavior while in college and data on degree type, graduation date, and major. The microdata on college coursetaking contain administrative course identifiers and a set of narrow subject descriptors that divide courses in 483 subject categories. We combine these records with publicly available administrative data that maps course identifiers to CIP codes (FLDOE 2011) and course levels (FLDOE 2015). We then merge on AY 2000-2001 SUS average per credit cost data at the course level by two-digit CIP level. We match $96 \%$ of course to CIP codes and $74 \%$ to both CIP and course level. ${ }^{7}$ We replace cost data for courses with missing level information with CIP-specific averages. We replace cost data for students with missing CIP codes with average per credit costs across all majors and levels. We then compute total incurred direct, indirect, and total costs at the individual level, based on all courses each student takes within the state university system.

Our earnings data track students through early 2010, so the oldest students in the earnings records are 14 years past high school graduation, or approximately age 32 . For each individual we compute mean quarterly earnings over the period eight or more years following high school completion, so the youngest individuals in our earnings outcome sample are approximately age 26. Our earnings specifications take either this variable or its log as the outcome of interest. Our earnings measure has a number of limitations in this application. First, as mentioned above, we do not observe earnings for individuals who leave Florida. Because missing values of earnings may reflect both true zeros and students who do have earnings but leave the state, we consider only quarters with positive earnings values when computing means. We observe no earnings records for about $25 \%$ of individuals in our data. We discuss the relationship between earnings

\footnotetext{
${ }^{7}$ Note that our administrative course records date to the 2010s, while our microdata on student course-taking span the early 1990s through late 2000s. Merge rates are less than one because some courses offered in, say, 2000 do not appear in 2015 administrative data. Merge rates for CIP code are high because we observe narrow subject classification in both the administrative records and the course microdata. This allows us to merge CIP classifications to microdata at the subject level even where we do not observe a direct course match. Merge rates for level are relatively low because there is no level classification in the microdata, so we only observe level where we can precisely match a course from the late 1990s through mid 2000s to a course offered in 2011.
} 
censoring and major choice in section 5.4. Second, it does not capture differential growth in earnings across majors over time. Two majors with similar average earnings over the immediate post-college period could have different long-run trajectories. Third, because we cannot differentiate between non-employment and out-of-state migration, we cannot compute labor force participation rates, which may differ by major. When computing the present discounted value of cross-major earnings differences, we scale our estimated level effects by the number of elapsed quarters times 0.84 , the labor force participation rate for college graduates aged 25-34 in 2005 (NCES 2015, Table 501.50).

We consider two samples of students in our earnings and cost analysis. The first consists of students who enroll in a state university in their first year following high school graduation and go on to complete a bachelor's degree program at a state university. We use data on these students for the cross-major earnings and cost comparisons. The second consists of students who satisify the initial enrollment criterion but do not graduate. We consider earnings and cost outcomes for these students in Section 5.6. ${ }^{8}$

To address concerns related to censoring and the lack of late- and mid-career data in the Florida earnings data, we supplement our earnings analysis with estimates of mid-career earnings from the ACS. We use data from the 2009 to 2012 ACS surveys, and estimate earnings value added specifications that control for gender, race, and labor market experience within the set of individuals aged 24 to 59 and who had earnings of at least $\$ 2000$ per year. These estimates closely parallel those discussed in Altonji et al. (2012), except that we aggregate majors into coarser categories to correspond with two-digit CIP codes. We discuss results obtained using these data in parallel with our findings using the Florida data extracts.

\section{Costs, returns, and net PDVS}

\subsection{Methods}

Our analysis focuses on earnings and cost 'value added' specifications of the form

$$
y_{i}=\theta_{f(i)}^{y}+X_{i}^{\prime} \beta^{y}+e_{i}^{y}
$$

and

$$
c_{i}=\theta_{f(i)}^{c}+X_{i}^{\prime} \beta^{c}+e_{i}^{c} .
$$

\footnotetext{
${ }^{8}$ Due to changes in data access policies, we no longer have access to the microdata used to estimate the earnings models and construct the cost estimates. Consequently, for part of the analysis we are limited to using data extracts based on the microdata. We were unable to compute summary statistics for our earnings and costs analysis samples.
} 
Equation 6 estimates the effects of college major, indexed by $f$, on earnings outcome $y_{i}$. We consider specifications with both log earnings and earnings levels as the dependent variable. In the Florida data $X_{i}$ is a set of controls for individual and institutional characteristics. It includes race, gender, free lunch status while in high school, a dummy variable equal to one for students born in the US, a third degree polynomial in high school GPA, and third degree polynomials in SAT math and reading scores. It also includes sets of dummy variables for high school graduation cohort and the university a student attends. We estimate this specification within the sample of students who graduated from college. The coefficients of interest here are the $\theta_{f(i)}^{y}$, which correspond to the effect of major on earnings conditional on other student observables. Although our control set is fairly rich, students may sort into majors in ways that are correlated with unobservable determinants of income levels. Students may also sort into majors on the basis of comparative advantage. We therefore interpret our estimates cautiously: they may not capture the earnings changes that would occur if students were arbitrarily selected to move from one degree to another. This concern is stronger is the case of the ACS earnings regressions, which do not control for test scores, high school grades or free lunch status while in high school.

Equation 7 has a control set identical to the earnings regression, but takes as an outcome the total costs a student incurs while in college. We regression-adjust costs to account for the fact that some students may take more or less expensive routes through college regardless of major. For example, students with lower high school grades may take more remedial courses. Consequently, our estimates of degree costs by major hold constant differences across majors in student characteristics.

We use estimates of $\theta_{f}^{y}$ and $\theta_{f}^{c}$ from versions of equations 6 and 7 where the dependent variables are earnings and cost levels to compute present discounted values of earnings and cost streams. We compute the present discounted value of a stream of earnings by a) multiplying the estimated quarterly earnings effects by four to get annual effects, b) scaling annual effects by 0.84 (the average rate of labor force participation amongst college graduates 25-34 in 2005) to approximate labor force participation rates, and c) computing the discounted value of a stream of payments of this size beginning in the eighth year following high school graduation and continuing until some stop-time $T$. We discount values back to the year before students begin college at an interest rate of 5\% per year. We focus on two stop times: age 32 (14 years after HS completion), and age 45. The former corresponds to the limit of our support for earnings outcomes in the Florida data. We choose the latter to approximate earnings effects through mid-career. We also present estimates through age 55. To compute the PDVs of college costs, we assign estimated total cost effects evenly across the first four years following high school completion and discount back to the year of completion. This discounting will result in values that are too large for students who stay in college longer than four years, but too small for students who front-weight credits to their first few years of college. 


\subsection{Distribution of credits and graduates over majors}

The upper panel of Figure 1 shows the shares of undergraduate credits by major for the 2000-2001 school year, sorted from smallest to largest share. In total, we observe cost data for 4.9 million student credit hours, or roughly 164,000 student FTEs. Business courses are the most common, accounting for $14.3 \%$ of all credit hours. The next most popular fields are social science and education, which make up $11.7 \%$ and $8.5 \%$ of credit hours, respectively. The most common type of STEM credit is math. Math courses make up $7.9 \%$ of all credit hours. Within the STEM category, math is followed by Engineering, Biology, and Computer Science, which each make up between $3.7 \%$ and $3.8 \%$ of all credit hours.

The distribution of degree programs for graduating majors is strongly but not perfectly correlated with the distribution of credits. The lower panel of Figure 1 plots the log share of credits on the horizontal axis against the log share of graduates on the vertical axis. Most majors track the 45-degree line, which we plot for reference. A handful of majors- Math, Physical Science, Languages, and Philosophy- fall far below the line. Many students take courses in these subjects but do not major in them. The most common major, Business, accounts for nearly one quarter of all graduates.

\subsection{Cost heterogeneity}

As shown in the upper panel of Figure 2, spending per credit varies widely by field. Table 2 presents descriptive statistics about the distribution of costs over field, while Table 3 shows spending for each field individually. Per credit spending on direct instruction in the highest-cost major, engineering, is $\$ 322,272 \%$ higher than per credit spending in the lowest-cost major, parks and recreation. It is $237 \%$ higher than the field with the second lowest cost, mathematics. Levels of total instructional spending are roughly twice as high, but both the ordering of degree programs and relative magnitudes of differences (in percentage terms) are quite similar. For example, the total cost per credit of an engineering course is $\$ 569,209 \%$ more than the $\$ 184$ per credit cost of a mathematics credit. Though STEM fields like Engineering, Health Sciences, and Engineering Technology are among the highest-cost fields, not all high-cost fields are STEM fields. For example, visual art, architecture, and library science all have above-average pre-credit costs. The (credit-weighted) interquartile range of the total cost per credit distribution is $\$ 120$, or $43 \%$ of the median per credit cost, and the standard deviation of per credit cost distribution is $\$ 89$.

The cost differences we observe suggest that some majors cross-subsidize others. Under the assumption that levels of institutional aid are consistent across majors, we can read off the relative net costs of credit hours in different majors to the institution by subtracting per credit tuition from major-specific per credit

costs. Per credit average in-state tuition in the State University System was \$108 (2014 dollars) in the 2000-2001 academic year, including mandatory fees (FLBOG 2001). The upper panel in Figure 2 shows that tuition covers direct instructional costs in only a handful of majors, and does not cover total costs in 
any of them. Relative to tuition, the per credit subsidy in engineering degrees was $\$ 461$, compared to a $\$ 76$ subsidy for mathematics credits. The credit-weighted average subsidy level is $\$ 191$ per credit. Relative to this average, classes in fields like business, psychology, and computer science cross-subsidize fields in engineering, health, education, and the visual arts.

We observe similar patterns across fields when assessing the costs on a per graduate basis. Compared to an average total degree cost of $\$ 39,184$, engineering graduates incur costs of $\$ 62,297$ over their schooling career while graduates in business (the third lowest cost major) incur costs of $\$ 31,482$. The graduateweighted interquartile range is $\$ 11,511$, equal to $32 \%$ of the median value. The graduate-weighted correlation between total per credit costs and total incurred costs for graduates is 0.89 , while the credit hour weighted correlation is 0.75 . The values of total costs we compute are very similar to results reported for a subset of degrees in Johnson (2009) based on the 2003-2004 graduating cohort from the Florida SUS. For example, Johnson reports average total costs for graduates of $\$ 40,339$ (after converting to 2014 dollars), similar to our estimate of $\$ 39,184$, and he reports average costs for engineering graduates of $\$ 60,703$, compared to our estimate of $\$ 62,297$.

\subsection{Earnings heterogeneity}

Earnings outcomes also differ across majors. Figure 3 and Table 4 show mean log earnings and regression adjusted log earnings differences based on the Florida data. Values are expressed relative to the omitted education major. Without adjusting for student covariates, education majors earn an average of \$10,279 per quarter that they work, or roughly $\$ 41,000$ if they work for the entire year. This is $42.6 \log$ points less than students in the highest-earning major, Engineering Technology, and 39.8 log points more than the lowest earning major, art. Value added measures that control for student observable characteristics yield similar patterns. Engineering technology majors earn $43.5 \%$ more than education majors with similar observable characteristics, while art majors earn 37\% less. Though STEM majors such as engineering technology, engineering, computer science, and health science are among the highest-paying majors, nonSTEM majors like business are also high paying, while other STEM majors like biology, math, and the physical sciences offer lower returns. Overall, the graduate-weighted standard deviation of estimated earnings effects is $0.17 \mathrm{log}$ points, and the difference between the lowest- and highest-earning degrees is $80 \log$ points, or $123 \%$.

Our findings are qualitatively similar to those reported in Altonji et al. (2012) in that the gap between the highest- and lowest-earning majors is comparable in size to the college wage premium. However, our finding of fairly low returns (relative to education) in math and the physical sciences is inconsistent with results displayed there and in many of the studies they survey. This discrepancy may reflect real differences in program quality, labor market conditions, or student sorting in our data versus in the nation 
as a whole. ${ }^{9}$ The availability of a richer set of controls in the Florida data probably plays a role, and one should be mindful of the fact that the standard errors are quite large for some of the Florida parameters. It is also possible that our findings are affected by differential censoring across majors or of our focus on early-career outcomes. Table A2 describes difference in rates of earnings censoring by major.

To supplement our coefficient estimates, we present parallel estimates of equation 6 using nationallyrepresentative ACS data for college graduates aged 24 to 59. These estimates control for gender, race, a third degree polynomial in age, and interactions between these variables. Table 4 reports coefficient estimates and standard errors. The graduate-weighted correlation between the Florida and ACS estimates is 0.678. The most salient difference between the Florida estimates and the ACS estimates is that in the ACS data education is a relatively low-earning degree program, while in the Florida data it falls in the middle of the earnings effect distribution. Physical Science, Life Science, and Math majors also perform well in the ACS data relative to the Florida data. The ACS estimates of the effects of physical sciences, math and life sciences and most other majors are lower relative to education even when we restrict the ACS sample to persons who were born in and living in Florida at the time of the survey and between the ages of 26-32 (roughly the age range of the Florida data), though we note that the Florida-only ACS estimates are noisy. We will continue the comparison of Florida and ACS earnings estimates when comparing earnings to costs. Estimates are based on the Florida administrative earnings data unless stated otherwise. Figure A1 plots the estimated coefficients from the Florida data on the horizontal axis against ACS coefficients on the vertical axis.

\subsection{Net returns}

Table 5 and Figure 4 compare regression-adjusted earnings and costs for graduates from different majors and compute present discounted values of net effects for graduates. We focus on levels specifications to facilitate simple comparisons between earnings and costs. We find that a) differences across major in net PDVs are primarily driven by earnings outcomes, but that $b$ ) differences in costs have a sufficiently large effect on PDVs to make an economically significant difference in relative returns.

Figure 4 compares value added measures of earnings effects (measured in levels) on the horizontal axis to returns net of costs through age 32 on the vertical axis. As with the earnings estimates above, we measure earnings level effects and net PDVs relative to the values observed for education, which we normalize to zero. Because the PDVs of earnings and costs are weakly correlated (the graduate-weighted correlation between these variables is 0.21 ), PDVs net of costs on average rise one-to-one with PDVs of earnings, closely tracking the 45-degree line, which we plot for reference. The highest-earning degrees,

\footnotetext{
${ }^{9}$ It is worth noting the Florida was particularly hard hit by the Great Recession. Oreopoulos et al. (2012) and Altonji et al. (2016b) show that labor market conditions have a substantial effect on the early career earnings of college graduates that vary across fields.
} 
like engineering technology, engineering, and computer science, have the highest PDVs net of costs, while the lowest-earning degrees have the lowest net PDVs.

Deviations from the 45-degree line are driven by cost differences across degrees. One way to quantify the importance of these differences is to compare variation in costs to variation in the distribution of earnings. The graduate-weighted standard-deviation of the cost PDV distribution is $\$ 7,187$, roughly one quarter the size of the graduate-weighted standard deviation of the earnings PDV distribution $(\$ 28,845)$. It is $13.5 \%$ of a standard deviation of the graduate weighted PDV of earnings effects extrapolated out to age 45. It is $15.6 \%$ and $15.7 \%$ using the PDV through age 45 and age 55 (respectively) of earnings effects based on the ACS data. The graduate-weighted interquartile range of the cost PDV distribution is $\$ 10,582$, and the difference between the highest and lowest-cost degree is $\$ 27,184$. The former value is somewhat larger than the difference between the 10th and the 25th percentile of the distribution of earnings PDVs through age $32(\$ 6,940)$ and somewhat smaller than the difference between the 25 th and 50th percentile $(\$ 13,934)$.

It is also helpful to draw concrete comparisons between earnings and cost rankings of specific degree programs. For example, the PDV of early-career earnings is more than $\$ 32,000$ higher for engineering majors than for business majors. However, higher costs for engineers lead these two majors to have net PDVs that are close to equal. Similarly, business and health majors have earnings PDVs that are essentially the same, but lower costs for the business degrees lead to a higher net NPV. Shifting focus to the lowerearning degree programs, we can make similar comparisons. For example, English degrees have higher net NPV than physical science despite fairly similar earnings, because costs are much lower. Broadly speaking, we observe a relatively small number of degree programs where earnings are substantially higher than in Education. Using a difference of $10 \log$ points as a cutoff, these degrees are in the fields of Health, Business, Computer Science, Engineering, Engineering Technology, and (somewhat surprisingly) Library Science. Cost differences are sufficient to reorder these programs relative to one another based on early career earnings, but not to shift them to lower values than the set of lower-return programs. When we consider PDVs of earnings to age 45 or beyond, rank reversals are rare, but the cost differentials are still substantial.

\subsubsection{Returns per instructional dollar}

If we believe that estimates of earnings and cost effects are causal, that earnings effects are not heterogeneous across individuals, and that our cost estimates are representative of differences in marginal costs, then the above discussion identifies the earnings return net of costs of adding an additional graduate in a given field. The effects of additional spending on a per dollar basis are also of interest. While the net earnings returns on a per-degree basis are relevant for individuals who face the true costs of degree provision, or for policymakers maximizing the sum of net earnings returns who must choose how to allocate an 
additional graduate, net earnings returns on a per-dollar basis are relevant for policymakers trying to figure out how get the most net value given a fixed budget for additional students.

To consider per dollar effects we first fix earnings and cost intercepts by conditioning on a specific set of covariates. We consider the case of a Hispanic, female, US-born student from the Miami-Dade school district in the 2000 high school graduating cohort who attends Florida State, had unweighted high school GPA of 3.5, and scored 500 on the math and verbal sections of her SATs. We compute predicted PDVs of earnings and costs for this individual based on estimated effects from Table 5 and divide the earnings PDV by the cost PDV to get a per-dollar measure of the return to spending in each major. Figure 5 plots estimates of per-dollar returns by major through age 32 as a fraction of the per-dollar return to education on the vertical axis versus estimated log earnings effects on the horizontal axis. We normalize the return for the education major to zero. We report estimates for each major in Table 6.

The graduate-weighted correlation between per-dollar spending effects and estimated earnings effects is 0.52. Health and Engineering majors, where earnings returns are large on a per graduate basis, have per-dollar returns similar to those observed in education, math, philosophy, and language degrees, where earnings are much lower. The degrees that fare best on a per-dollar basis are business and computer science, which are both high-earning and relatively cheap. These majors have per-dollar earnings returns that are $60 \%$ to $80 \%$ higher than in education degrees. The degrees that fare worst are Architecture, Art, and the Physical Sciences, which are fairly expensive and have relatively low earnings; these majors have per-dollar earnings returns that are $20 \%$ to $30 \%$ below that for education.

We also consider measures of per-dollar returns computed using ACS earnings data. Paralleling Figure 5, Figure A2 plots ACS estimates of log earnings effects on the horizontal axis earnings PDV per spending dollar on the vertical axis. We obtain per-dollar earnings PDV estimates using the procedure described above but substituting ACS earnings estimates for Florida earnings estimates and use earnings through age 45. A similar pattern emerges in the sense that high-earning, low-cost degrees like business and computer science have the highest per-dollar PDVs. As in the Florida analysis, Health and Engineering degrees have fairly similar per-dollar PDVs to education despite much higher earnings. Most degrees, including Math, Life Sciences, and Social Science have higher per-dollar PDVs relative to education in the ACS data than in the Florida analysis. This pattern reflects the difference in estimates of earnings effects that we discussed earlier, particularly the lower return to the education major in ACS data.

\subsection{Dropouts}

The analysis above focuses on college graduates. Students who attend college but do not graduate incur costs as well, but may have very different labor market outcomes. Unfortunately, we do not observe declared major prior to graduation. Nor do we observe specific patterns of course-taking for non-graduates 
that might allow us to divide students by major prior to graduation. However, we are able to observe the total costs incurred by students who obtain varying amounts of course credits. Specifically, we observe results from specifications of the form

$$
c_{i}=\theta_{t(i)}^{c}+X_{i} \beta^{c}+e_{i}^{c}
$$

and

$$
y_{i}=\theta_{t(i)}^{y}+X_{i} \beta^{y}+e_{i}^{y}
$$

in the sample of students who enroll in a state university but do not complete their degree. Here $y_{i}$ is earnings, again measured between eight and fourteen years following high school completion, $c_{i}$ is total spending on courses taken by student $i, \theta_{t(i)}$ is a set of dummy variables corresponding to amounts of total completed credits, and $X_{i}$ are the same set of individual covariates described in section 5.1. The categories indexed by $t$ are divided into 24 -credit bins. This is the minimum number of credits required to maintain full-time enrollment for two semesters, so we describe persistence in college for non-completers in terms of years. We focus on earnings effects in levels to make the comparison with costs more straightforward. Recall that earnings are measured on a quarterly basis.

Table 7 shows estimates of earnings and cost effects of the $\theta_{t}$ for students who persist through their second, third, and fourth or more year relative to those who drop out within the first year. Costs increase rapidly with additional years of attendance, rising by $\$ 5,419$ in the second year to $\$ 11,915$ in the third year, and to $\$ 28,276$ for students who stay for three or more years but do not graduate. In contrast, earnings for non-completers do not rise much with additional years of attendance. We cannot reject the null hypothesis that non-completers who remain in college for two or three years have earnings equal to those who remain in college for only one year. Students who remain in college for three or more years earn \$261 more per quarter than those who complete at most one year's worth of credits. However, the PDV of these earnings gains is $\$ 4,812$ through age $32,18.3 \%$ of the PDV of the additional costs these students incur.

One possible explanation for our finding of limited earnings gains per additional year of schooling in the dropout sample is that students who persist in an SUS institution but do not complete are likely to move out of state (for example, to complete college at a different institution). We note that a) this would not mechanically reduce estimated earnings effects, which are computed using earnings for stayers only, and $b$ ) rates of earnings censoring decline with additional schooling in the dropout sample. We display estimates of equation 9 with an indicator variable for missing earnings outcomes as the dependent variable in the third column of Table 7.

Dropouts account for a substantial share of overall costs in our data. Within our sample of students who 
enroll in college in the year following high school graduation, 38,336 students go on to graduate and are included in our analysis of college major returns, while 19,375, or one third of the total sample, do not receive a BA from any institution in the SUS. Based on average per graduate expenditures of $\$ 39,184$ and average per-dropout expenditures of $\$ 16,101$, dropouts account for $17.2 \%$ of total expenditures in our sample. This estimate is similar to internal calculations conducted by the FLDOE and reported in Johnson (2009). The FDLOE calculations indicate that $19.6 \%$ of costs for entering first-time-in-college students in the 2001-2002 school year accrued to students who had not graduated from any SUS institution by 2006-2007. Due to data limitations, allocating dropouts in a way that would allow the costs of dropouts to be attributed to specific majors is a topic we leave for future work.

\section{Trends in costs per credit}

\subsection{Overall trends in spending}

Our analysis thus far captures a snapshot of instructional expenditures at a point in time. Results indicate that average earnings returns per graduate and per dollar differ substantially across majors. This implies that a given increase (or decrease) in instructional expenditures may have very different implications for total income depending on how it is allocated across fields of study. In this section, we analyze changes in expenditures and course-taking over the 1999-2013 pattern through the lens of our findings on differential returns and subsidies across majors. Our goal is to understand how the allocation of resources and subsidies across majors changed over this period. Under the strong assumption that per-person and per-dollar returns to major did not change over the period, and that our estimates of average returns and costs are predictive of marginal returns and costs, this exercise can provide insight into the overall return to instructional spending. We note, however, that changes in spending may also reflect changes in production technology. For example, expenditures may decline without any change in student earnings if professors become able to teach more students in the same time without a reduction in quality. We return to this point in section 7.

We begin by documenting overall trends in course-taking and spending. Figure 6 shows how total credits, total instructional spending, and average spending per student credit hour changed over the 1999-2013 period. Total undergraduate credit hours rose by roughly $50 \%$ over the period, from approximately 4.6 million in 1999 to 7 million by 2013. This represents a rise from 150,000 FTEs to 233,000. Expenditures, shown in the middle panel, also rose, though less steadily and by a lower percentage. Total expenditures on undergraduate instruction rose roughly $25 \%$ from 1999 to 2013 , from $\$ 1.4$ billion to $\$ 1.7$ billion. The result of these simultaneous trends was a $16 \%$ fall in per credit spending over the period. It is worth noting that per credit spending patterns correspond to the business cycle, with large drops in spending during downturns in 2001 and 2007-2010. 


\subsection{Major specific trends in credits and spending}

The allocation of student credit hours and expenditures also shifted between 1999 and 2013. Figure 7 breaks down enrollment and spending trends by major for the 12 largest majors. Together, these 12 majors account for $75 \%$ of credits over the period. The upper panel of Figure 7 shows the ratio of each major's share of total credits in a given year to its credit share in 1999, which we normalize to 1 . The middle panel shows shares of total within-year spending over the same period, again normalizing the 1999 spending share to one. The lower panel shows total per credit expenditures by major relative to the 1999 per credit spending level. Within each panel, we split the majors into high, middle, and low cost groups using terciles of average per credit cost over the period.

Course enrollment trends vary by major within each cost category, and are not strongly related to the earnings or net PDVs we observe in our analysis of microdata. The degrees with the greatest increase in credit share over the period were, in order, biology, health science, psychology, and engineering. Recall from Table 5 that health science and engineering were among the majors with highest NPVs, while biology and psychology were near the middle of the PDV distribution. The degrees with the largest losses over the period were, in order, education, computer science, and English. Computer science was among the highest-return degree programs in our data by any measure, while English and education were near the middle of the PDV distribution.

Changes in cost shares bear a limited relationship to changes in credit shares for many degree programs. Focusing on the middle panel of Figure 7, we see that while the 52\% increase in credit share for biology courses was nearly matched by a $41 \%$ increase in cost share, the $42 \%$ increase in health science credits did not correspond to any rise in cost share (in fact, there was a $3 \%$ decline in cost share over the period), while the $17 \%$ rise in engineering credit share corresponded with a $17 \%$ decrease in cost share. Overall, a $10 \%$ within-major increase in credit hour share between 1999 and 2013 corresponded to a $5.8 \%$ increase in relative cost share, meaning that spending per credit share tended to decline in degrees with growing credit shares. On average, a 10\% shift in enrollment share between 1999 and 2013 was met by a 3.5 percent decline in average costs per credit. The lower panel of Figure 7 explores this relationship in more detail. Some of the highest-growth fields saw the largest declines in spending per credit. Average spending per credit in engineering and health science fields fell by over 40\% between 1999 and 2013. Conversely, the only field of the 12 considered here which had higher average spending per credit in 2013 than in 1999 was English literature, which saw one of the biggest declines in credit share.

To explore the relationship between spending per credit and number of credits, we regressed log spending per credit by course level, field, institution, and year on log credits, including course level, field, institution, and year indicators as controls (not reported). The coefficient on log credits is -0.178 (.008) for direct costs and -0.134 (.007) for total costs. We also looked for evidence that, at least in the short run, cost per credit respond asymmetrically to increases and decreases in enrollment in a given subject area. One might expect 
this if some staff inputs (particularly tenure track faculty) and classroom facilities are fixed in the short run. We regressed one year changes in log total spending per credit on one-year changes in the log of total credits, allowing the coefficient to depend on the sign of the change in credits. The results are sensitive to choice of weights, and so we do not draw any firm conclusions.

\subsection{Staff inputs and spending per credit}

In this subsection we explore the degree to which changes in spending per credit reflect changes in faculty and staff inputs. The association reflects the extent to which educational inputs are adjusted as demand for credits varies, and will also depend on policy choices about class size and instructor type. Some caution is called for in interpreting the relationship between credits and inputs, because causality may also run in the other direction - from education inputs to supply of credits for student to take. We focus on the University of Florida because we do not have data after 2007-2008 for the other schools in a usable form.

Figure 8 reports the trend in costs per credit for the same groups of high, middle, and low cost majors at the University of Florida for the years $1999-2000$ to 2012-2013. ${ }^{10}$ The figure shows a substantial decline in spending per credit and is broadly similar to that in Figure 7 for all universities. Figure 9 reports the trends in faculty FTE per credit hour for the University of Florida by cost grouping. Faculty inputs in the high- and middle-cost majors show a decline, with the exception of Computer Science and Literature. All low-cost majors show a decline.

Figure 10 aggregates across all undergraduate majors. The upper panel of the figure shows that faculty per credit drops by about $16 \%$ between 2000 and 2012. This decline parallels the drop in the number of faculty FTEs devoted to instruction, displayed in the lower panel. Graduate Assistant-Adjunct Faculty (GA-AF) per credit rose by about $21 \%$ during the period, particularly between 2009 and 2012. GA-AF FTEs rose by similar amount. Support staff per credit and in total rose by about $13 \%$ over the period. Use of GA-AF and support staff rose prior to the Great Recession, dropped during the Great Recession, and then recovered.

We decompose the change in log total spending per credit over the 2000-2012 period into a component driven by changes in instructional inputs and a component unexplained by instructional inputs. The decomposition is based on coefficient estimates from a regression of spending per credit by course level, field, and year on the three instructional input measures and year indicators. The regression also controls for course level and field of study. We weight using the course shares of each field of study in a given year. Consequently, more popular fields get more weight. The coefficient on log faculty per credit is 0.317. The coefficients on log GA-AF per credit and log support staff per credit are 0.156 and 0.188 ,

\footnotetext{
${ }^{10}$ We report data through 2012-2013 rather than $2013-2014$ as in the previous figures for comparability with staffing data, which is available through 2012-2013.
} 
respectively.

We use the coefficients on the instructional inputs along with the weighted means of the input measures to compute an index for each year summarizing the effect of inputs on costs. Figure 11 displays the trend in the actual value of log spending per credit and the trend holding inputs per credit at the level in 2000. Spending per credit drops by $0.08 \log$ points between 2000 and 2001, then steadily rises between 2001 and 2006 to about 0.06 above 2000 level. This increase is followed by a decline during the Great Recession. Overall, costs per credit fall by $0.21 \mathrm{log}$ points between 2000 and 2012. About half of the decline is accounted for by instructor inputs, and about half is a decline holding instructor inputs constant. Many factors, including changes in compensation, a shift in toward lower paid instructors within the three instructor categories, and more intense utilization of other inputs may have contributed to the share not determined by changes in counts of faculty, GA-AF and support staff per credit. A full analysis of this issue is an interesting topic for future research.

\section{Conclusion}

This paper studies the differences in costs of producing course credits and graduates across majors and compares them to differences in earnings outcomes. We have two main findings. First, costs per credit and per graduate vary widely by major. The average cost per graduate across all fields is $\$ 39,184$; the standard deviation of costs is $\$ 7,187$. This is equal to one quarter of the standard deviation of crossmajor differences in earnings PDVs through age 32 and $13.5 \%$ of a standard deviation of the graduate weighted PDV of earnings effects extrapolated out to age 45. While major specific earnings estimates differ somewhat across data sets, they show that differences in costs are sufficiently large to have an economically significant effect on the relative net returns to various majors. The importance of costs as a determinant of relative returns is even more striking on a per-dollar basis. For example, the mean PDV of earnings for an engineering major is similar to that for a much lower-earning education major per dollar of instructional cost. Earnings returns are highest per dollar of instructional expenditure for inexpensive but high-earning majors like computer science and business.

An important question for public policy is whether higher education institutions could become more productive by shifting the allocation of resources across majors given some fixed budget constraint. If one is willing to make the assumption that our estimates of earnings effects and average costs capture returns and costs for marginal students under such a policy, then one way to view our findings is as describing what would need to be true about major-specific externalities and non-pecuniary utilities for current tuition setting and enrollment policies to yield an optimal outcome. Specifically, at a utility maximizing allocation, the marginal dollar spent should have equal value in any field of study. This means that observed perdollar differences in earnings net of costs must be balanced out by per-dollar differences in non-pecuniary 
utility and utility from externalities. Our findings indicate that, if schools are currently allocating funding optimally across majors, it must be the case that degrees in fields with low per-dollar returns such as art, architecture, and even engineering and the physical sciences, must offer larger non-pecuniary and public benefits than programs in fields like computer science, business, or law. It is not impossible that universities are finding this balance, but it does seem a priori unlikely. Given some set of beliefs about non-pecuniary and public returns by field, possible levers for equalizing marginal returns across degree programs are changes in tuition, or shifts in supply large enough to change skill prices.

Our second main finding is that recent trends in per credit spending differ by major. Per credit spending fell 16\% between 1999 and 2013, with especially rapid declines in majors with increasing number of credit hours. These include high-return majors like engineering and health science, where per credit funding fell by more than $40 \%$ over the period. Though we cannot rule out that these declines reflect increased pedagogical efficiency on a per-dollar basis as opposed to any reduction in program quality, other research suggests that reduced expenditures at the level of the institution lead to declines in student outcomes. Bound and Turner (2007) and Bound, Lovenheim, and Turner (2010) highlight the extent to which reductions in per-student resources at two-year colleges and less-selective four-year public universities depress college completion rates in the aggregate. The declines in median per-student expenditures they observe are on the order of 5\% to $15 \%$ depending on institution type. Our findings suggest that these average declines may mask larger declines in some majors than others, and that these large declines may occur in high-return areas. Overall declines in graduation rate may understate the degree to which declining investment reduces human capital accumulation, because the mix of graduates across fields may also be shifting. The effects of changes in major-specific educational expenditures on the majors students choose and earnings outcomes conditional on major choice is a topic for future study.

Finally, our results highlight how policies that fix tuition across majors create systems of cross-field crosssubsidies. A natural question is how changes to this cross-subsidy system would affect the private and public returns to higher education. One approach would be to shift to major-specific tuition while keeping spending fixed (or not altering projected spending paths). As discussed in Stange (2015), Ehrenberg (2012) and CHERI (2011), an increasing number of universities allow tuition to vary for at least some majors. While some universities use these policies to more closely match tuition to instructional costs in majors like nursing and engineering, others reduce tuition to encourage students to enroll in 'high-need' majors regardless of costs. The majors labeled 'high need' are often STEM majors with fairly high costs as well. Our results suggest that measures of need based on private labor market outcomes should take into account differences in production costs. We also emphasize that earnings returns may not reflect public returns. An alternate approach is to reallocate spending across majors while keeping tuition as it is. The effects of such a policy depend on the relative returns to a dollar of spending across majors. Further research on the marginal effects of additional subject-specific dollars would be valuable here. 


\section{References}

Altonji, J.G., E. Blom, and C. Meghir, "Heterogeneity in Human Capital Investments: High School Curriculum, College Major, and Careers," Annual Review of Economics, 2012, 4, 185-223.

, P. Arcidiacono, and A. Maurel, "Chapter 7 - The Analysis of Field Choice in College and Graduate School: Determinants and Wage Effects," in E. Hanushek, S. Machin, and L.Woessmann, eds., Handbook of the Economics of Education, Vol. 5, Elsevier, 2016, pp. 305 - 396.

Altonji, Joseph G, Lisa B Kahn, Jamin D Speer et al., "Cashier or Consultant? Entry Labor Market Conditions, Field of Study, and Career Success," Journal of Labor Economics, 2016, 34 (S1).

Alvarez, Lizette, "Florida May Reduce Tuition for Select Majors," New York Times, December 9th 2012.

Arcidiacono, P., "Ability Sorting and the Returns to College Major," Journal of Econometrics, 2004, 121, 343-375.

Beffy, M., D. Fougere, and A. Maurel, "Choosing the Field of Studies in Postsecondary Education: Do Expected Earnings Matter?," Review of Economics and Statistics, 2012, 94, 334-347.

Berger, M.C., "Predicted Future Earnings and Choice of College Major," Industrial and Labor Relations Review, 1988, 41, 418-429.

Bound, J. and S. Turner, "Cohort crowding: How Resources Affect Collegiate Attainment," Journal of Public Economics, 2007, 91 (5), 877-899.

, M.F. Lovenheim, and S. Turner, "Why Have College Completion Rates Declined? An Analysis of Changing Student Preparation and Collegiate Resources," American Economic Journal: Applied Economics, 2010, 2 (3), 129.

Chevalier, A., "Subject Choice and Earnings of UK Graduates," Economics of Education Review, 2011, $30,1187-1201$.

Conger, Sharmila Basu, Alli Bell, and Jeff Stanley, "Four-State Cost Study. Revised.," State Higher Education Executive Officers, 2010.

Cornell Higher Education Research Insitute (CHERI), "2011 Survey of Differential Tuition at Public Higher Education Institutions," 2011.

Currie, Janet and Enrico Moretti, "Mother's Education and the Intergenerational Transmission of Human Capital: Evidence from College Openings," The Quarterly Journal of Economics, 2003, pp. $1495-1532$. 
Ehrenberg, Ronald G, "American Higher Education in Transition," The Journal of Economic Perspectives, 2012, 26 (1), 193-216.

Florida Department of Education (FLDOE) , “Statewide Course Numbering System,” 2015.

Florida Department of Education (FLDOE), “Course Catalog Active Courses,” October 272011.

Grogger, J. and E. Eide, "Changes in College Skills and the Rise in the College Wage Premium,” Journal of Human Resources, 1995, 30, 280-310.

Hamermesh, D.S. and S.G. Donald, "The Effect of College Curriculum on Earnings: An Affinity Identifier for Non-Ignorable Non-Response Bias," Journal of Econometrics, 2008, 144 (2), 479-491.

Hastings, J.S., C.A. Neilson, and S.D. Zimmerman, "Are Some Degrees Worth More Than Others? Evidence from College Admissions Cutoffs in Chile," NBER Working Paper, 2013, 19241.

Jaschik, Scott, “Obama vs. Art History,” Inside Higher Ed, January 312014.

Johnson, N., "What Does a College Degree Cost? Comparing Approaches to Measuring 'Cost per Degree'," Delta Cost Project white paper series, 2009.

_ _ "How Much Does It Cost Institutions to Produce STEM Degrees?," The Price and Cost of Science Degrees, 2013.

Kirkebøen, Lars, Edwin Leuven, and Magne Mogstad, "Field of Study, Earnings, and Self-Selection," The Quarterly Journal of Economics, 2016, p. qjw019.

Lange, Fabian and Robert Topel, "The Social Value of Education and Human Capital," Handbook of the Economics of Education, 2006, 1, 459-509.

McMahon, Walter W, Higher Learning, Greater Good: The Private and Social Benefits of Higher Education, Johns Hopkins University Press, 2009.

Middaugh, M.F., R. Graham, and A. Shahid, "A Study of Higher Education Instructional Expenditures: The Delaware Study of Instructional Costs and Productivity," Education Statistics Quarterly, 2003, 5 (2), 134-139.

Moretti, Enrico, "Estimating the Social Return to Higher Education: Evidence from Longitudinal and Repeated Cross-Sectional Data," Journal of Econometrics, 2004, 121 (1), 175-212.

National Center for Education Statistics (NCES), “Digest of Education Statistics: 2015,” 2015.

Olson, Steve and Donna Gerardi Riordan, "Engage to Excel: Producing One Million Additional College Graduates with Degrees in Science, Technology, Engineering, and Mathematics. Report to the President.," Executive Office of the President, 2012. 
Oreopoulos, P., T. von Wachter, and A. Heisz, "The Short- and Long-Term Career Effects of Graduating in a Recession," American Economic Journal: Applied Economics, 2012, 4, 1-29.

Stange, K., "Differential Pricing in Undergraduate Education: Effects on Degree Production by Field," Journal of Policy Analysis and Management, 2015, 34, 107-135.

State University System of Florida Board of Governors (FLBOG), "State University System of Florida Expenditure Analysis 1999-2000,” 2000.

__ , "State University System of Florida Expenditure Analysis 2000-2001,” 2001.

__ , "State University System of Florida Expenditure Analysis 2001-2002,” 2002.

__ , "State University System of Florida Expenditure Analysis 2002-2003,” 2003.

__ , "State University System of Florida Expenditure Analysis 2003-2004,” 2004.

__ , "State University System of Florida Expenditure Analysis 2004-2005,” 2005.

__ , "State University System of Florida Expenditure Analysis 2005-2006," 2006.

__ , "State University System of Florida Expenditure Analysis 2006-2007,” 2007.

__ , "State University System of Florida Expenditure Analysis 2007-2008,” 2008.

__ , "State University System of Florida Expenditure Analysis 2008-2009,” 2009.

, “State University System of Florida Expenditure Analysis 2009-2010,” 2010.

, “State University System of Florida Expenditure Analysis 2010-2011,” 2011.

, “State University System of Florida Expenditure Analysis 2011-2012,” 2012.

, “State University System of Florida Expenditure Analysis 2012-2013,” 2013.

Thomas, James, "What Do Classroom Spending Decisions Reveal about University Preferences?,” Duke University Working Paper, 2015.

Webber, Douglas A., "The Lifetime Earnings Premia of Different Majors: Correcting for Selection based on Cognitive, Noncognitive, and Unobserved Factors," Labour Economics, 2014, 28, 14-23.

Zimmerman, Seth D, “The Returns to College Admission for Academically Marginal Students," Journal of Labor Economics, 2014, 32 (4), 711-754. 


\section{Tables and figures}

Figure 1: Credits and graduates by major
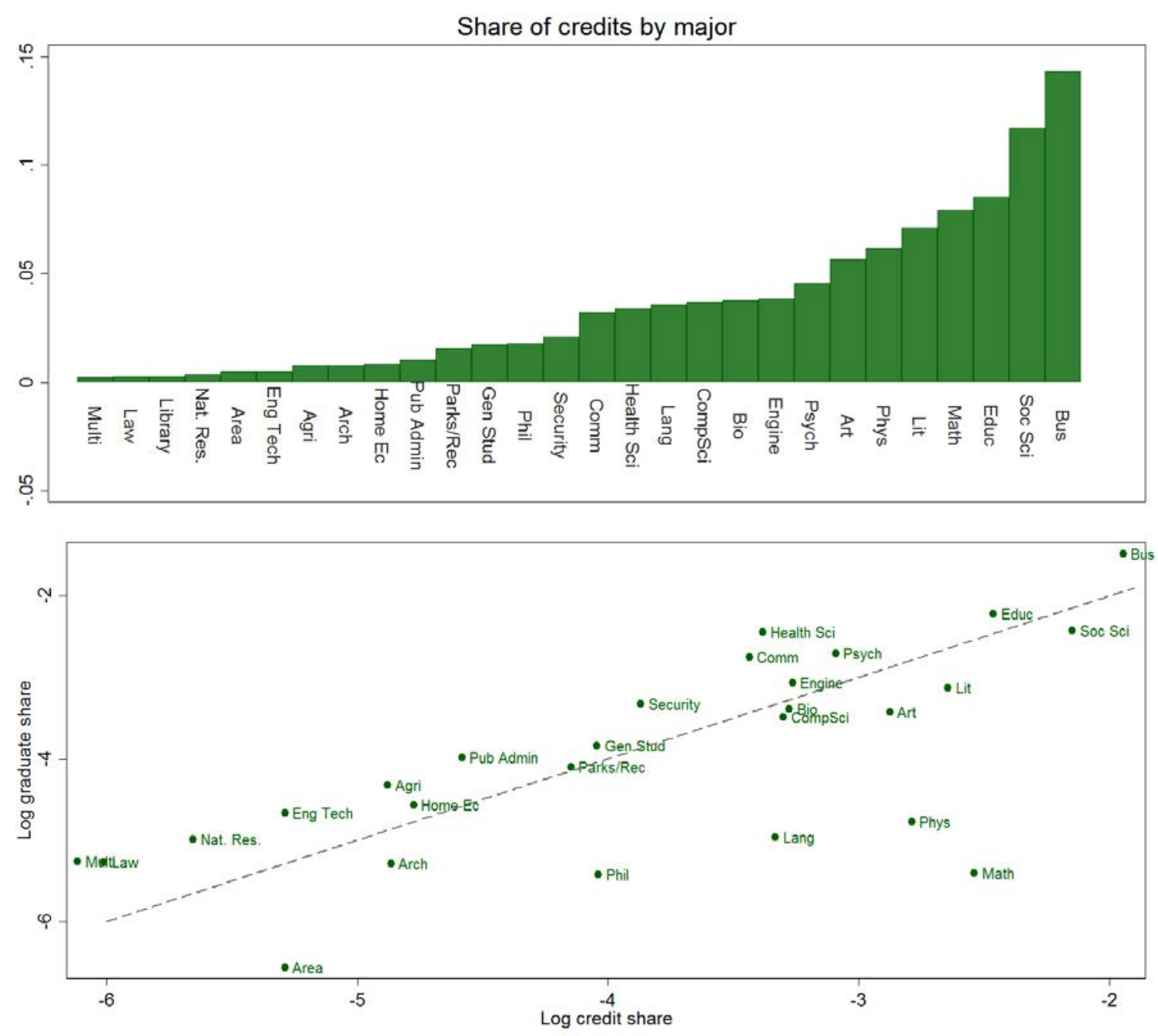

Upper panel: share of undergraduate-level credits by major in AY 2000-2001. Sample includes all Florida SUS institutions. Majors are divided by two-digit CIP code. Lower panel: log share of credits by major AY 2000-2001 on horizontal axis. Log share of graduates by major for AY 2000-2001 on vertical axis. Source: authors' calculations from FLBOG expenditure and enrollment reports and graduate reports. 
Figure 2: Costs by major
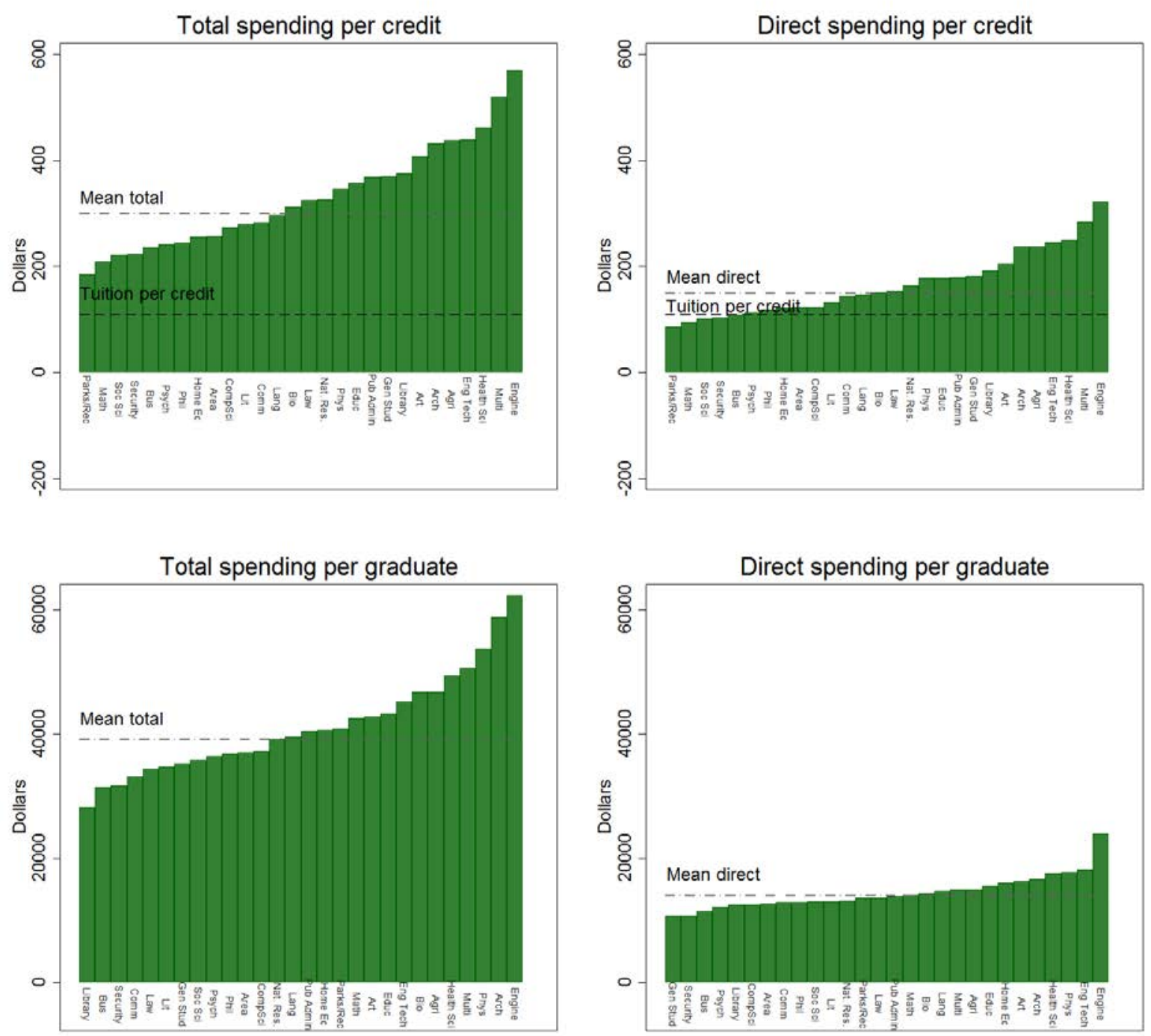

Upper panel: total and direct spending per credit by major, AY 2000-2001. Lower panel: total and direct spending per graduate. Upper panel uses administrative per credit data for undergraduate-level credits averaged across SUS system. Tuition per credit line represents (deflated) 2000-2001 in-state per credit tuition and mandatory fees. 'Mean total' and 'Mean direct' lines are credit-weighted average of per credit costs across majors. Lower panel: average total and direct course costs over course of study for graduates in microdata extracts. 'Mean total' and 'Mean direct' lines are graduate-weighted cost averages. 
Figure 3: Log earnings by major
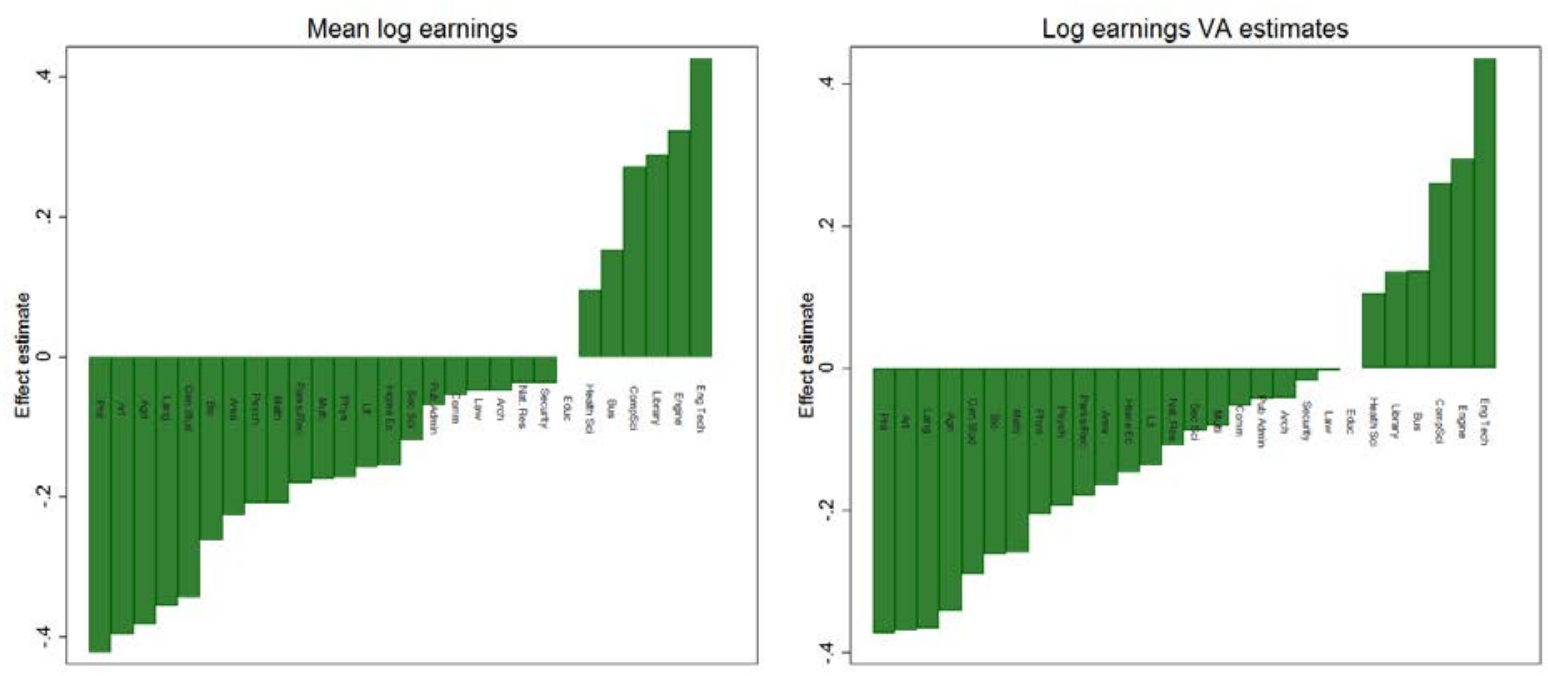

Raw (left) and regression-adjusted (right) log mean earnings estimates for FL graduates in microdata extracts. Coefficient estimates expressed relative to omitted education category. $\mathrm{N}=28469$ in left panel and 26189 in right panel.

Figure 4: Earnings vs. per graduate net value by major

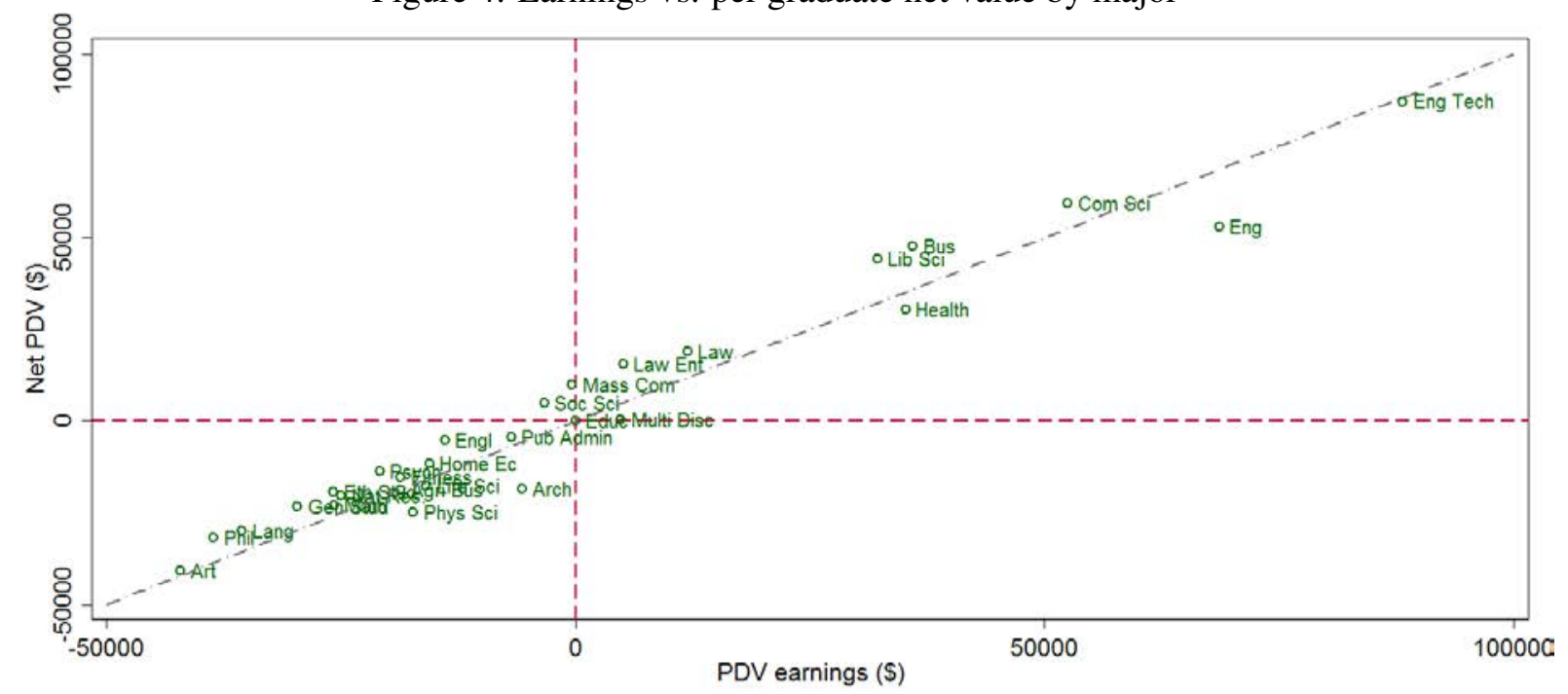

Horizontal axis: PDV of earnings effects through age 32 by major. Vertical axis: net PDV (earnings less costs) through age 32. Earnings and cost estimates come from equations 6 and 7 with quarterly earnings and total costs as dependent variables. Earnings and costs normalized to zero for education major. See section 5.1 for a discussion of PDV calculation in more detail. 
Figure 5: Earnings vs. per instructional dollar net value by major

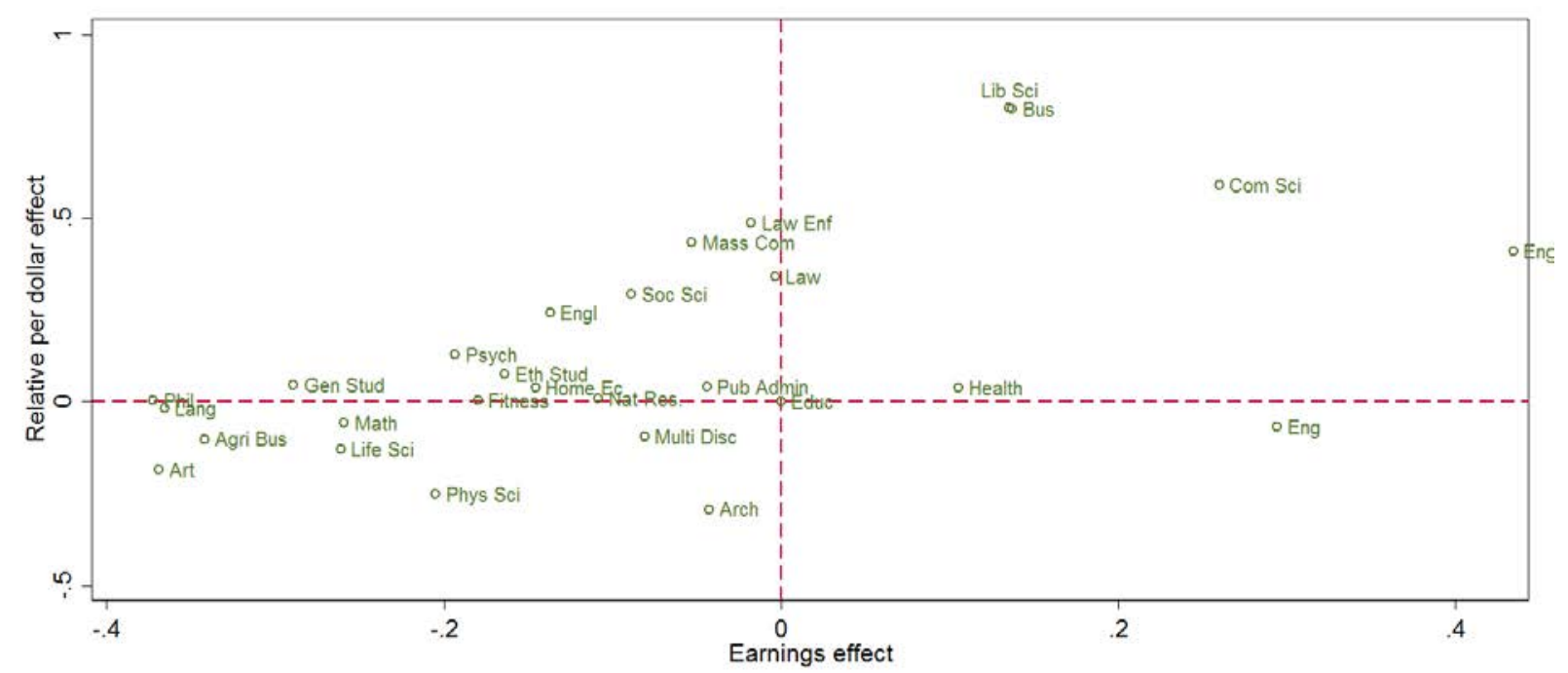

Horizontal axis: estimated log earnings effects from equation 6 relative to omitted education category. Vertical axis: ratio of earnings to cost PDVs relative to ratio for reference education category, conditional on $X_{i}=x$, i.e.: $\frac{\operatorname{EARNPDV}_{j}(x) / \operatorname{COSTPDV}_{j}(x)}{\operatorname{EARNPDV} V_{\text {educ }}(x) / \operatorname{COSTPDV} V_{\text {educ }}(x)}-1$. See section 5.5 for more details on per-dollar effect calculations.

Figure 6: Trends in credits and spending
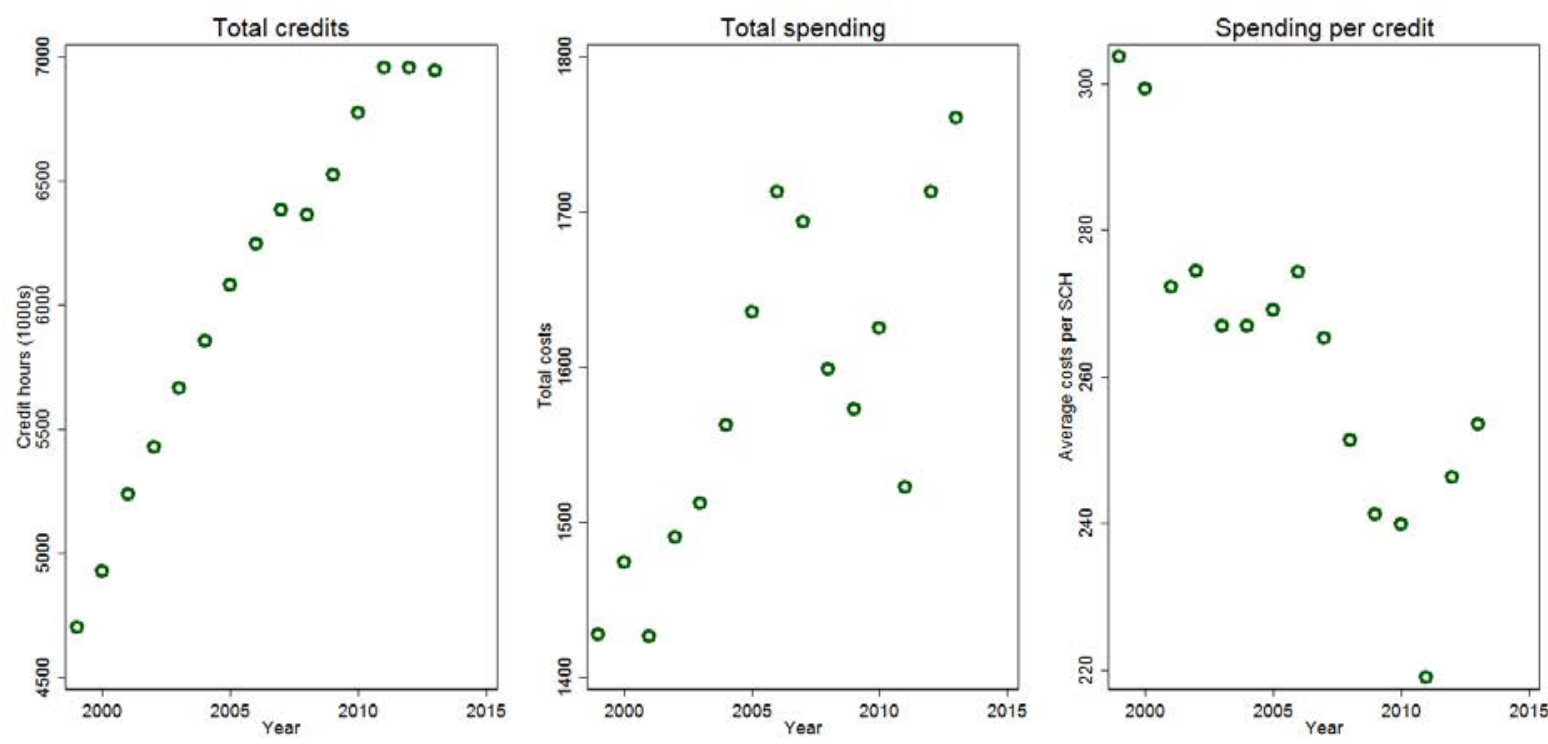

Trends in total credits, total expenditures, and per credit expenditures over time. Undergraduate level credits only. Statistics computed over all SUS campuses. Credit hours reported in 1000s; total costs in millions of 2014 USD. Source: FLBOG expenditure reports. 

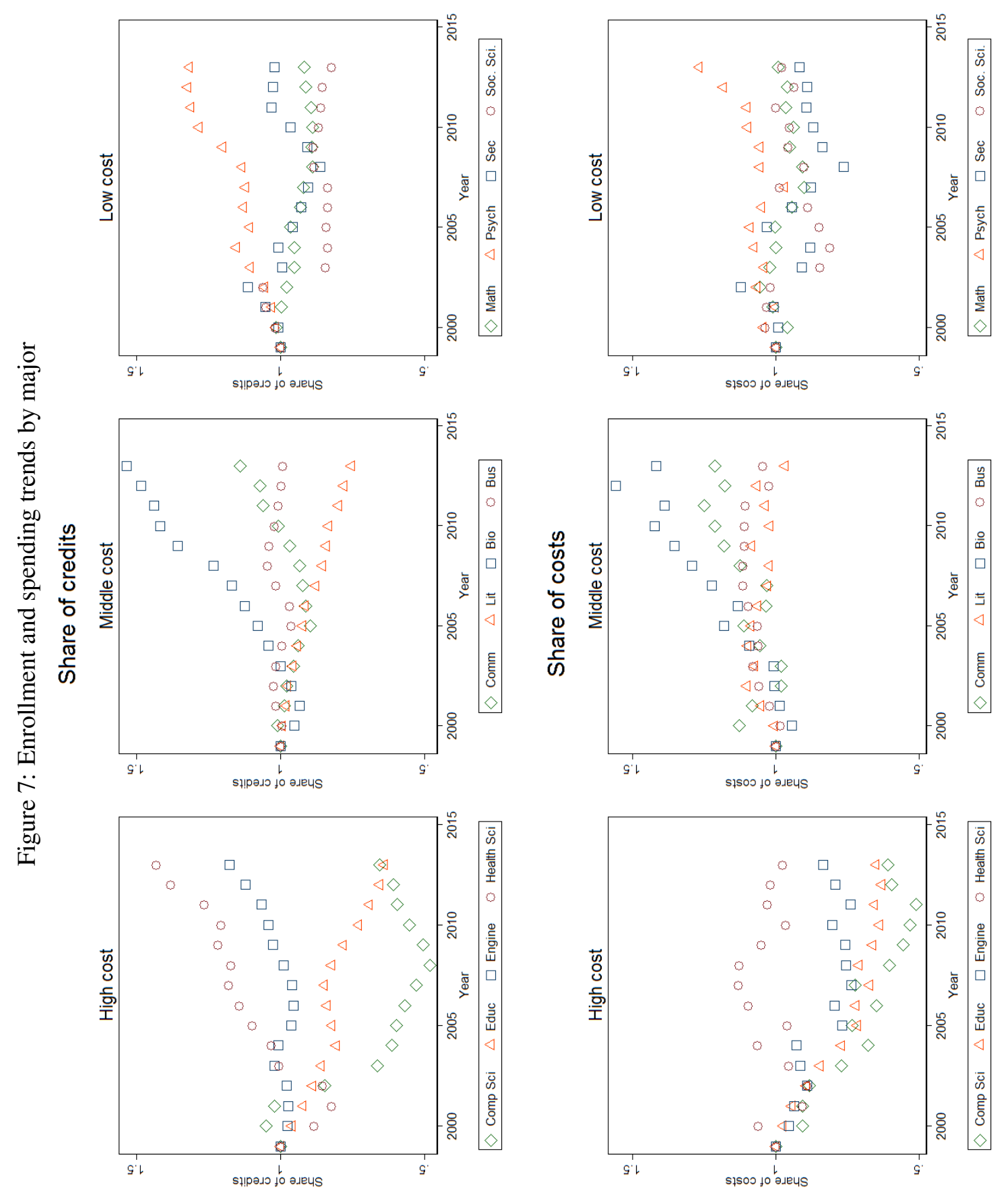

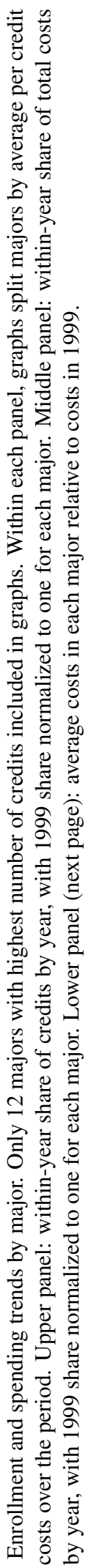




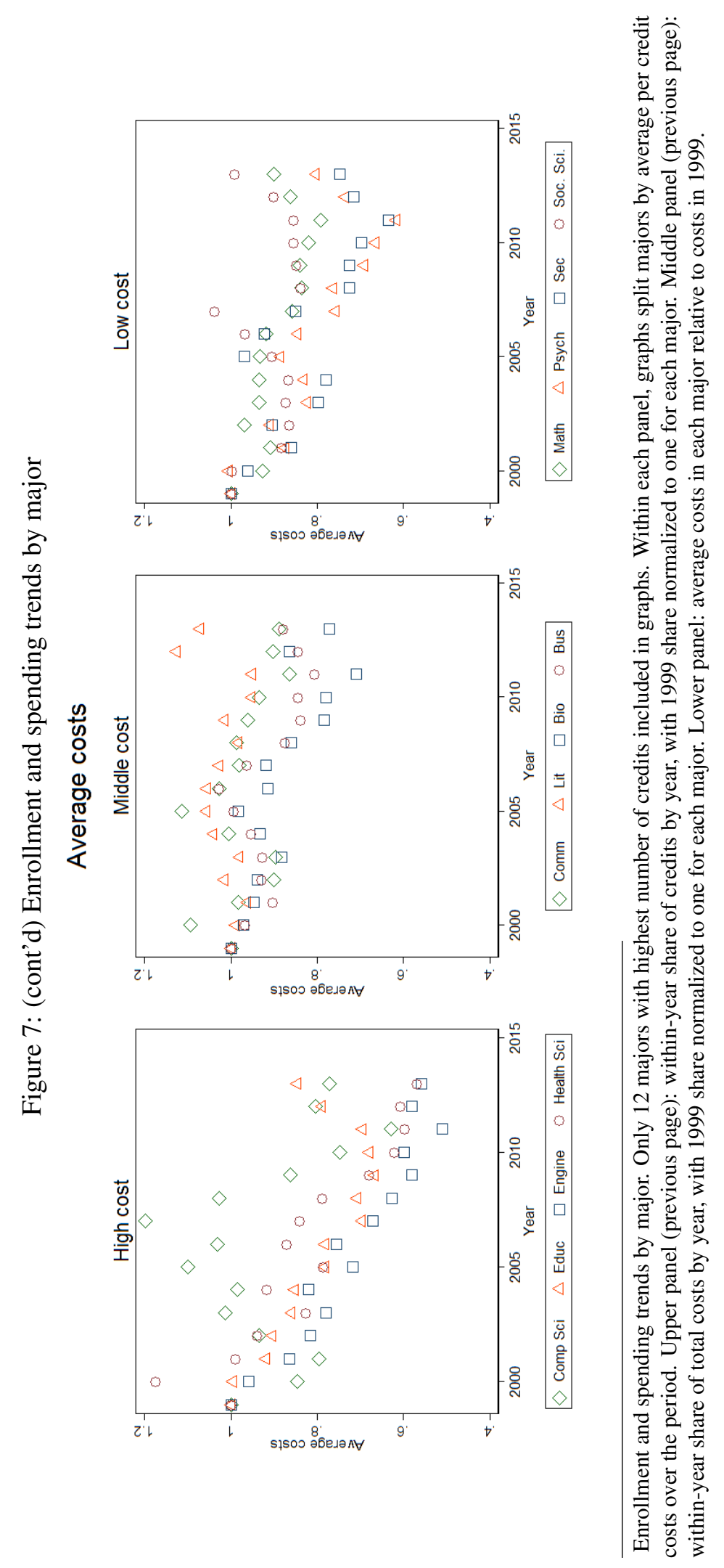




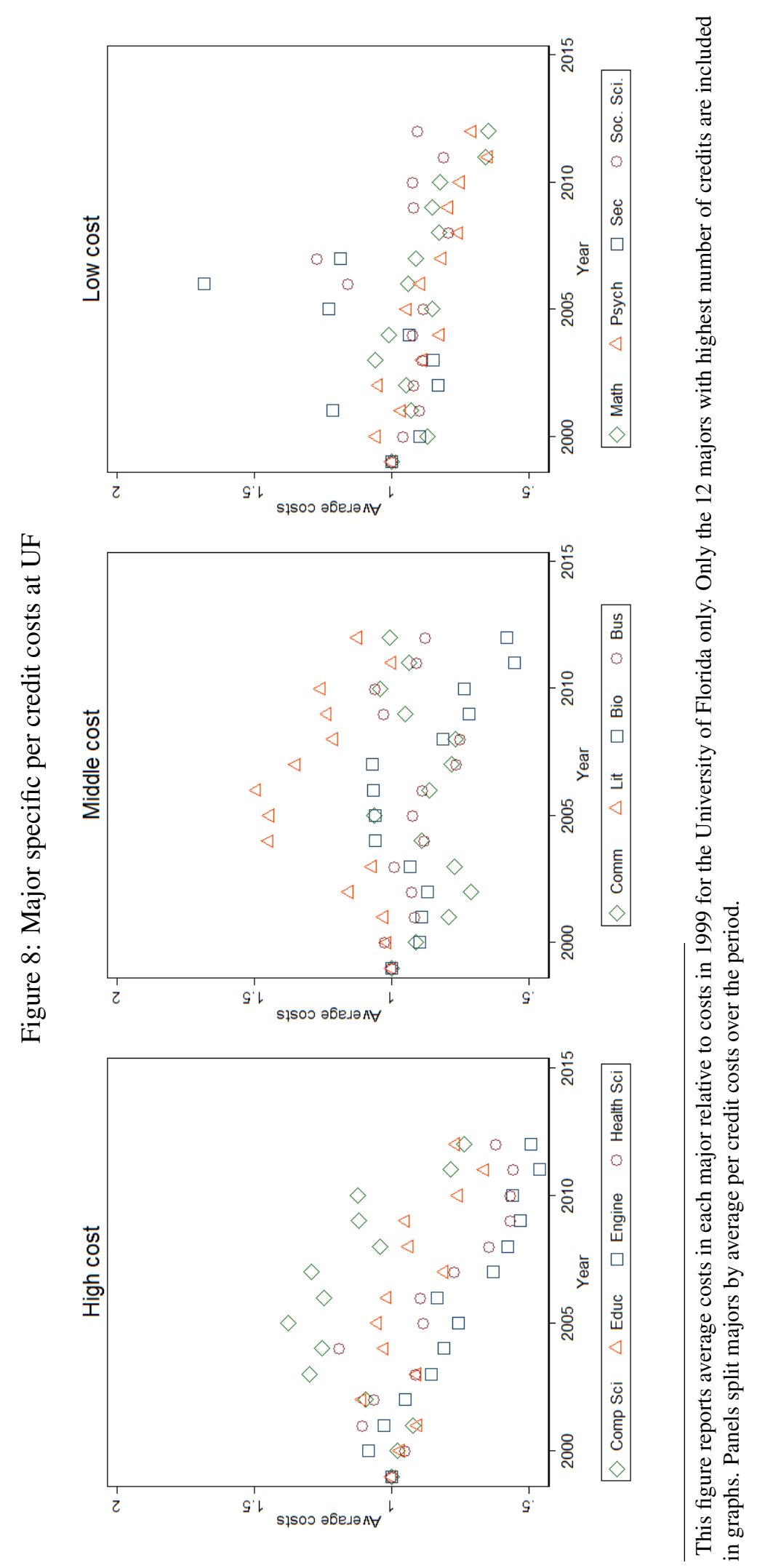




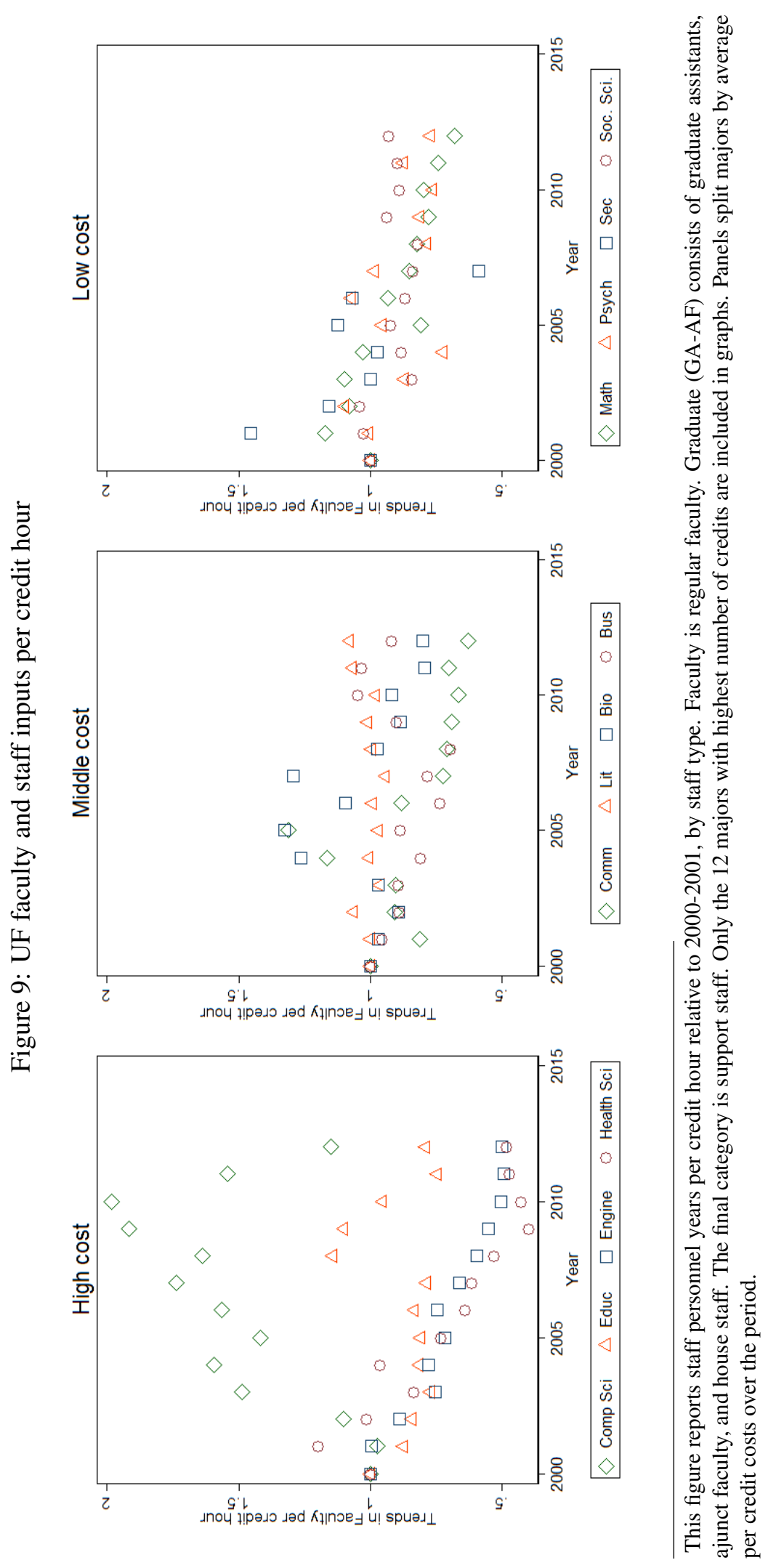


Figure 10: Trends in Faculty Inputs, All Undergraduate Courses, U. of Florida
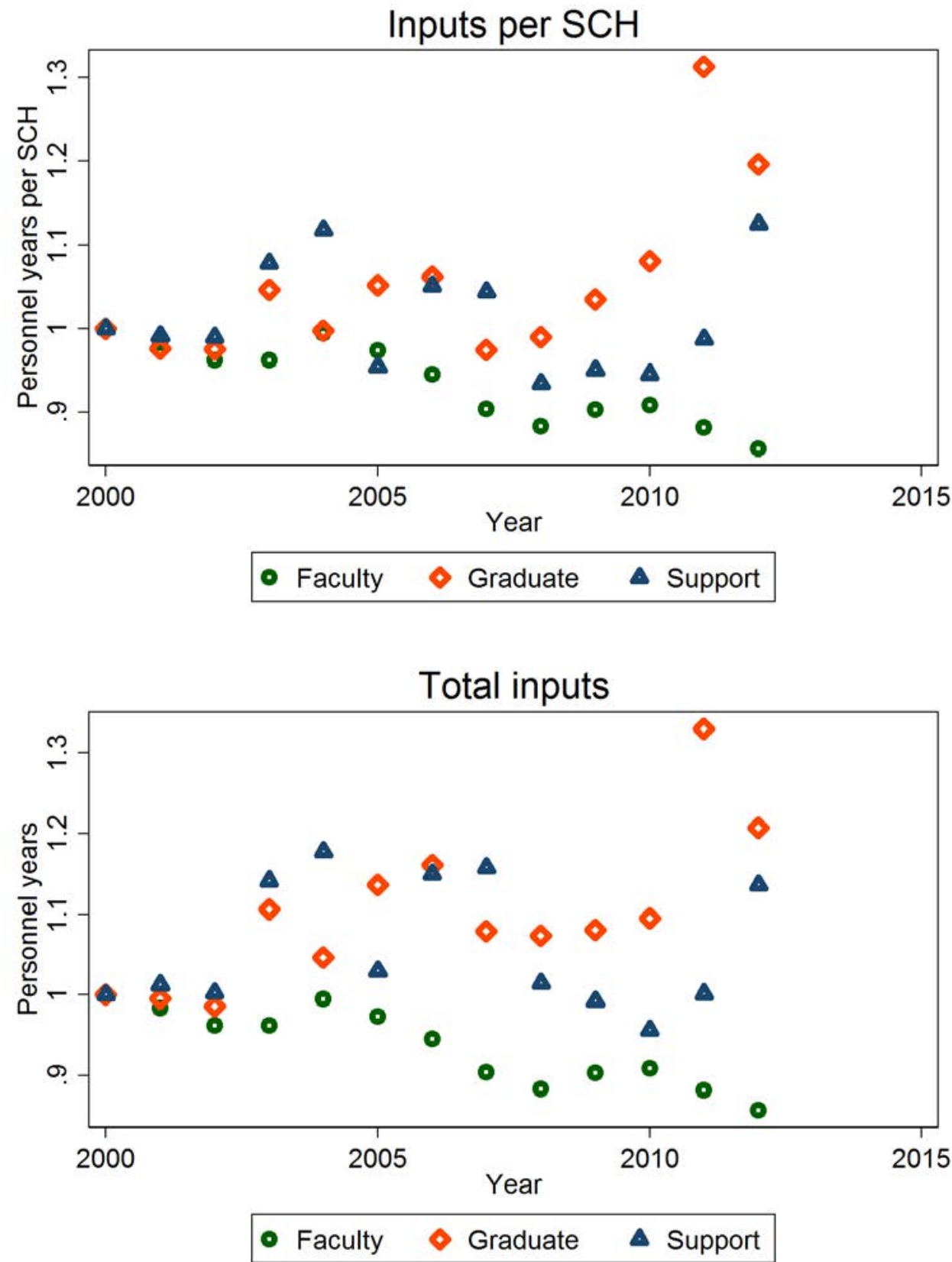

The top figure and bottom figure report trends in instructional personnel years per credit and in instructional personnel years. The values are for all undergraduate courses at the University of Florida for the 2000-2001 to 2012-2013 academic years. The values are relative to 2000-2001, which is normalized to 1 . 'Graduate' is graduate assistants, adjunct faculty, house staff, and other. It is referred to as GA-AF in the text. 'Support' is support staff. 
Figure 11: UF spending per credit on undergraduate instruction

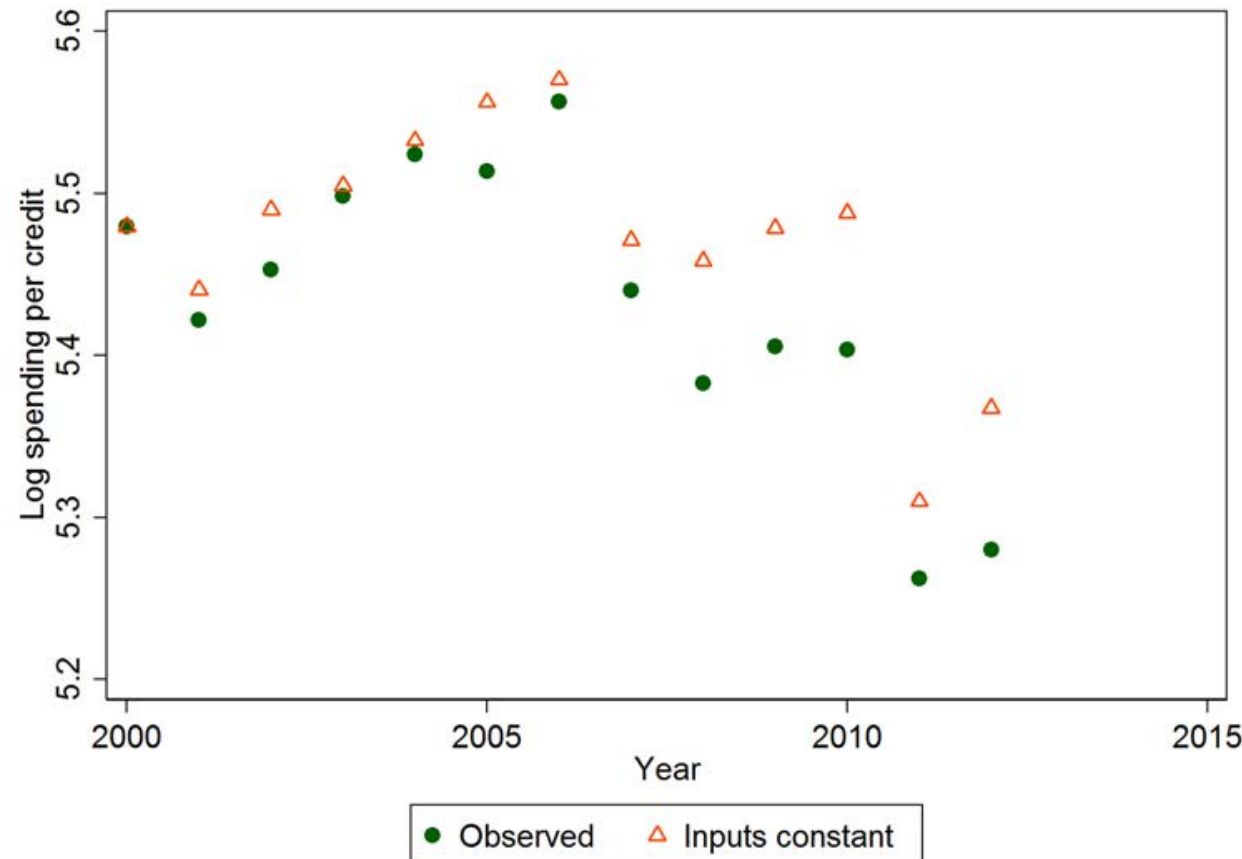

The figure reports observed log spending per credit and log spending per credit holding instructional inputs constant at their 2000-2001 values. See section 6.3 for a description of the adjustment procedure. The data for all undergraduate courses at the University of Florida. 
Table 1: Spending by type, AY 2000-2001

\begin{tabular}{lccccccc} 
Type & Direct & Indirect & Total & Credit hours & Direct PC & Indirect PC & Total PC \\
\hline A. Instruction & & & & & & & \\
Lower & 232 & 273 & 505 & 2147 & 108 & 127 & 235 \\
Upper & 502 & 467 & 969 & 2781 & 181 & 168 & 349 \\
Graduate & 371 & 199 & 570 & 803 & 462 & 248 & 710 \\
All instruction & 1106 & 939 & 2044 & 5731 & 193 & 164 & 357 \\
& & & & & & & \\
B. Non-instruction & & & & & & & \\
Research & 282 & 155 & 437 & & & & \\
Public Service & 31 & 15 & 46 & & & & \\
\hline
\end{tabular}

Spending and credit hours by direct expenditure category in SUS system, AY 2000-2001. Units in left three columns are millions of USD. Units in credit hours column are 1000s of credits. Per credit (PC) expenditures in dollars. Panel A: instructional expenditures by level and type. 'Upper' and 'Lower' are undergraduate level expenditures. Panel B: non-instructional expenditures. See Section 4.1 for a discussion of direct and indirect expenditures.

Table 2: Spending variation by major, AY 2000-2001

\begin{tabular}{lcccc} 
& Direct PC & Total PC & Direct per grad & Total per Grad \\
\hline mean & 149 & 299 & 14009 & 39184 \\
sd & 54 & 89 & 3013 & 8025 \\
p5 & 95 & 209 & 10792 & 31482 \\
p10 & 102 & 222 & 11501 & 31482 \\
p25 & 109 & 236 & 11501 & 31689 \\
p50 & 123 & 280 & 12958 & 36369 \\
p75 & 178 & 357 & 15597 & 43200 \\
p90 & 205 & 407 & 17600 & 49335 \\
p95 & 250 & 461 & 18196 & 58764 \\
\hline
\end{tabular}

Distribution of per credit and per graduate expenditures by major for SUS system AY 2000-2001. N=28. Graduate data from extract with $\mathrm{N}=38336$. The left two columns describe credit-weighted per credit direct and total expenditures for undergraduate credits. Right two columns describe graduate-weighted direct and total per graduate expenditures for graduates in microdata extracts. All values in dollars. p5 is the 5th percentile of cost distribution, p10 the 10th, and so forth. 
Table 3: Spending by major

\begin{tabular}{lcccclcccc} 
& \multicolumn{2}{c}{ Per credit } & \multicolumn{2}{c}{ Per graduate } & \multicolumn{2}{c}{ Per credit } & \multicolumn{2}{c}{ Per graduate } \\
Major & Total & Direct & Total & Direct & Major & Total & Direct & Total & Direct \\
\hline Fitness & 184 & 87 & 40775 & 13587 & Bio. & 311 & 154 & 46735 & 14319 \\
Math & 209 & 95 & 42543 & 14077 & Nat. Res. & 326 & 164 & 39141 & 13137 \\
Soc Sci & 222 & 102 & 35744 & 12958 & Gen. Stud. & 370 & 177 & 35173 & 10743 \\
Security & 223 & 103 & 31689 & 10792 & Educ. & 357 & 178 & 43200 & 15597 \\
Phil & 245 & 109 & 36899 & 12873 & Law & 325 & 179 & 34338 & 13672 \\
Home Ec. & 255 & 112 & 40534 & 16074 & Phys. Sci. & 346 & 183 & 53716 & 17736 \\
Bus. & 236 & 119 & 31482 & 11501 & Pub. Admin & 368 & 193 & 40417 & 13823 \\
Psych. & 241 & 121 & 36369 & 12189 & Art & 407 & 205 & 42710 & 16222 \\
Engl. & 280 & 123 & 34656 & 12979 & Agri. Bus. & 437 & 237 & 46765 & 14986 \\
Area Stud. & 256 & 123 & 36951 & 12701 & Arch. & 432 & 238 & 58764 & 16599 \\
Lang. & 296 & 132 & 39448 & 14676 & Eng. Tech. & 439 & 246 & 45126 & 18196 \\
Comp. Sci. & 274 & 144 & 37236 & 12572 & Health Sci. & 461 & 250 & 49335 & 17600 \\
Comm & 282 & 147 & 33070 & 12841 & Inter. & 519 & 283 & 50569 & 14950 \\
Lib. Sci. & 376 & 151 & 28223 & 12480 & Engine. & 569 & 322 & 62297 & 23937 \\
\hline
\end{tabular}

Per credit and per graduate total and direct expenditures by major. Credit data for SUS system, AY 2000-2001. Graduate data for microdata extract. Graduate data from sample with $\mathrm{N}=38336$. All values in dollars. For distribution summary statistics see Table 2. 
Table 4: Earnings by major

Florida Administrative Records ACS 2009-2012 ACS Age 26-32

\begin{tabular}{lccccccc} 
& & & \multicolumn{4}{c}{ Age 24-59 } & \multicolumn{2}{c}{ Born and Live in Florida } \\
\hline Field & Mean & Coef & SE & Coef & SE & Coef & SE \\
Agri & -0.383 & -0.342 & 0.094 & 0.050 & 0.007 & 0.202 & 0.087 \\
Nat. Res. & -0.038 & -0.108 & 0.072 & 0.072 & 0.008 & -0.107 & 0.091 \\
Arch & -0.049 & -0.042 & 0.058 & 0.139 & 0.010 & 0.079 & 0.107 \\
Area & -0.227 & -0.164 & 0.078 & 0.163 & 0.016 & 0.045 & 0.132 \\
Comm & -0.055 & -0.053 & 0.023 & 0.171 & 0.004 & 0.099 & 0.047 \\
CompSci & 0.272 & 0.260 & 0.032 & 0.379 & 0.004 & 0.148 & 0.074 \\
Educ & 0.000 & 0.000 & 0.000 & 0.000 & 0.000 & 0.000 & 0.000 \\
Engine & 0.324 & 0.295 & 0.026 & 0.428 & 0.003 & 0.238 & 0.048 \\
Eng Tech & 0.426 & 0.435 & 0.043 & 0.218 & 0.008 & 0.341 & 0.211 \\
Lang & -0.357 & -0.366 & 0.090 & 0.077 & 0.008 & 0.148 & 0.205 \\
Home Ec & -0.155 & -0.145 & 0.038 & 0.032 & 0.009 & 0.130 & 0.097 \\
Law & -0.050 & -0.003 & 0.072 & 0.120 & 0.020 & 0.073 & 0.133 \\
Lit & -0.159 & -0.137 & 0.026 & 0.092 & 0.005 & -0.051 & 0.067 \\
Gen Stud & -0.345 & -0.289 & 0.042 & 0.085 & 0.007 & -0.046 & 0.067 \\
Library & 0.289 & 0.135 & 0.214 & -0.044 & 0.030 & 0.055 & 0.026 \\
Bio & -0.263 & -0.261 & 0.034 & 0.239 & 0.004 & 0.184 & 0.059 \\
Math & -0.210 & -0.259 & 0.096 & 0.328 & 0.006 & 0.205 & 0.225 \\
Multi & -0.175 & -0.081 & 0.083 & 0.141 & 0.008 & 0.313 & 0.073 \\
Parks/Rec & -0.182 & -0.180 & 0.047 & 0.057 & 0.008 & 0.260 & 0.095 \\
Phil & -0.424 & -0.372 & 0.089 & -0.018 & 0.011 & 0.006 & 0.168 \\
Phys & -0.173 & -0.205 & 0.065 & 0.258 & 0.005 & -0.150 & 0.115 \\
Psych & -0.210 & -0.193 & 0.023 & 0.283 & 0.031 & -0.063 & 0.056 \\
Sec & -0.037 & -0.017 & 0.026 & 0.088 & 0.004 & -0.050 & 0.079 \\
Pub Admin & -0.069 & -0.044 & 0.033 & 0.125 & 0.005 & -0.047 & 0.058 \\
Soc Sci & -0.120 & -0.089 & 0.021 & 0.012 & 0.006 & 0.108 & 0.045 \\
Art & -0.398 & -0.369 & 0.036 & 0.244 & 0.004 & -0.077 & 0.062 \\
Health Sci & 0.096 & 0.106 & 0.023 & 0.004 & 0.005 & 0.232 & 0.047 \\
Bus & 0.153 & 0.137 & 0.017 & 0.330 & 0.003 & 0.140 & 0.036 \\
\hline & & & & & & &
\end{tabular}

Column 1 reports the mean of log earnings by major based on the Florida administrative records. Columns 2 and 3 report regression-adjusted estimates and standard errors. Estimates are relative to the Education major. Controls include indicators for ever graduated from high school, gender, Spanish language, U.S. born, black, Hispanic, and other race, ever received free or reduced lunch, cohort indicators, district indicators, university indicators, a cubic in high school gpa, and cubics in reading and math tests scores. Standard deviation/IQR of log means: 0.189/0.312. Standard deviation/IQR of VA estimates: 0.174/0.274. Unadjusted means from regression sample with $\mathrm{N}=28469$, adjusted from sample with $\mathrm{N}=26189$. Columns 4 and 5 report regressionadjusted estimates and standard errors using the ACS data for 2009-2012. The ACS sample is restricted to workers between the ages of 24-59 inclusive who earned at least \$2000/year. It includes controls for race/ethnicity interacted with gender, and a cubic in age interacted with gender, and dummies for masters, professional, and $\mathrm{PhD}$ degrees. The final two columns reports estimates after restricting the ACS sample to persons born in and living in Florida. 
Table 5: Per graduate PDVs of Costs, Earnings and Earnings Net of Costs, by Major

\begin{tabular}{|c|c|c|c|c|c|c|c|}
\hline \multirow[b]{2}{*}{ Major } & \multirow[b]{2}{*}{ Costs } & \multicolumn{4}{|c|}{ Florida Admin Earnings Data } & \multicolumn{2}{|c|}{ ACS } \\
\hline & & Earn 32 & NetPDV 32 & NetPDV 45 & NetPDV 55 & NetPDV 45 & NetPDV 55 \\
\hline Parks/Rec & -3.4 & -18.7 & -15.3 & -31.2 & -38.2 & 23.8 & 27.9 \\
\hline Math & -2.8 & -25.7 & -23.0 & -44.9 & -54.5 & 120.5 & 144.0 \\
\hline Soc Sci & -8.2 & -3.3 & 4.9 & 2.0 & 0.8 & 95.6 & 113.1 \\
\hline Security & -10.6 & 5.1 & 15.6 & 19.9 & 21.8 & 55.5 & 64.5 \\
\hline Bus & -11.6 & 35.9 & 47.6 & 78.2 & 91.6 & 114.5 & 135.2 \\
\hline Psych & -7.2 & -20.9 & -13.7 & -31.5 & -39.2 & 38.5 & 44.8 \\
\hline Phil & -6.9 & -38.6 & -31.7 & -64.6 & -78.9 & 0.3 & -1.0 \\
\hline Home Ec & -3.9 & -15.6 & -11.7 & -25.0 & -30.8 & 15.2 & 17.5 \\
\hline Area & -6.6 & -25.8 & -19.2 & -41.2 & -50.8 & 64.9 & 76.6 \\
\hline CompSci & -6.8 & 52.5 & 59.3 & 104.0 & 123.5 & 142.8 & 170.1 \\
\hline Lit & -8.7 & -13.9 & -5.3 & -17.2 & -22.3 & 41.6 & 48.3 \\
\hline Comm & -10.4 & -0.4 & 10.0 & 9.7 & 9.6 & 71.8 & 84.1 \\
\hline Lang & -5.8 & -35.6 & -29.8 & -60.2 & -73.4 & 33.3 & 38.9 \\
\hline Bio & 1.8 & -16.0 & -17.8 & -31.4 & -37.3 & 83.8 & 101.0 \\
\hline Law & -7.1 & 11.9 & 19.1 & 29.2 & 33.6 & 50.0 & 58.6 \\
\hline Nat. Res. & -4.7 & -25.0 & -20.3 & -41.6 & -50.9 & 30.6 & 35.8 \\
\hline Phys & 7.4 & -17.3 & -24.7 & -39.5 & -45.9 & 85.0 & 103.5 \\
\hline Educ & 0.0 & 0.0 & 0.0 & 0.0 & 0.0 & 0.0 & 0.0 \\
\hline Pub Admin & -2.5 & -6.9 & -4.4 & -10.3 & -12.8 & 6.8 & 7.7 \\
\hline Gen Stud & -6.5 & -29.7 & -23.2 & -48.4 & -59.5 & 37.1 & 43.2 \\
\hline Library & -12.0 & 32.2 & 44.2 & 71.6 & 83.5 & -3.8 & -7.0 \\
\hline Art & -1.3 & -42.1 & -40.8 & -76.7 & -92.3 & 2.6 & 2.9 \\
\hline Arch & 12.7 & -5.7 & -18.4 & -23.2 & -25.3 & 37.0 & 47.0 \\
\hline Agri & 0.2 & -18.6 & -18.8 & -34.7 & -41.6 & 17.8 & 21.4 \\
\hline Eng Tech & 1.1 & 88.2 & 87.1 & 162.2 & 195.0 & 77.2 & 92.9 \\
\hline Health Sci & 4.8 & 35.2 & 30.4 & 60.4 & 73.4 & 113.6 & 137.3 \\
\hline Multi & 4.5 & 4.8 & 0.3 & 4.3 & 6.1 & 46.0 & 56.2 \\
\hline Engine & 15.5 & 68.6 & 53.1 & 111.5 & 137.0 & 137.9 & 168.7 \\
\hline
\end{tabular}

Columns 1 and 2 report PDVs of costs and earnings (to age 32) by major. The remaining columns report PDV of earning net of costs, by major. Units are 1000s of USD. Column headings indicate the age through which earnings are considered. Column 2-5 is based on the Florida administrative earnings records. Columns 6 and 7 are based on the ACS. All estimates expressed relative to education major, which is normalized to have earnings and cost PDVs of zero. See Section 5.1 for details on NPV calculation. For the Florida date, SD/IQR of cost pdv: 7.19/10.58. SD/IQR of earning 32 PDV: 28.85/49.88. SD/IQR of Net PDV is 28.4/52.84 through age 32, 52.7/95.27 through age 45, and 63.40/113.88 through age 55. For the ACS data, the SD/IQR of Net PDV is 45.9/71.6 through age 45, and 54.87/90.33 through age 55. 
Table 6: PDVs by major per instructional dollar

\begin{tabular}{lclc} 
Major & $\begin{array}{c}\text { Earn PDV } \\
\text { per dollar }\end{array}$ & Major & $\begin{array}{c}\text { Earn PDV } \\
\text { per dollar }\end{array}$ \\
\hline Fitness & 0.003 & Law & 0.342 \\
Math & -0.056 & Nat. Res. & 0.009 \\
Soc Sci. & 0.294 & Phys. Sci & -0.252 \\
Sec. & 0.486 & Educ. & 0 \\
Bus. & 0.799 & Pub. Admin & 0.04 \\
Psych. & 0.129 & Gen Stud. & 0.047 \\
Phil. & 0.004 & Lib Sci & 0.801 \\
Home Ec. & 0.038 & Art & -0.185 \\
Area Stud. & 0.074 & Arch & -0.292 \\
Comp Sci & 0.59 & Agri & -0.101 \\
Engl. & 0.243 & Eng. Tech & 0.411 \\
Comm & 0.434 & Health Sci & 0.037 \\
Lang & -0.018 & Inter. & -0.095 \\
Bio & -0.129 & Engine. & -0.069 \\
\hline
\end{tabular}

PDVs through age 32 of per dollar of spending as fraction of PDV per dollar in education major at fixed $X_{i}=x$. See section 5.5 for details on per-dollar spending PDVs.

Table 7: Earnings and costs for non-completers

\begin{tabular}{lccc} 
Spell length & Earnings & Costs & Censoring \\
\hline 1-2 years & -21 & 5419 & -0.016 \\
& $(127)$ & $(54)$ & $(0.010)$ \\
2-3 years & 141 & 11915 & -0.033 \\
& $(143)$ & $(72)$ & $(0.011)$ \\
3+ years & 261 & 28276 & -0.084 \\
& $(130)$ & $(161)$ & $(0.010)$ \\
\hline
\end{tabular}

Earnings and costs for non-completers in extract data. Rows correspond to approximate lengths of enrollment before dropout. Earnings and cost columns present estimates of equations 3 and 4, respectively. Coefficients are expressed relative to omitted category of one or fewer enrollment years (within sample of students who enroll in university in year after high school completion). Earnings are quarterly earnings. Costs are total incurred costs. 'Censoring' outcome is a dummy equal to one if we do not observe mean earnings for a student. $\mathrm{N}=12,301$ in earnings regression and 16,651 in cost and censoring regression. 


\section{A Appendix: Additional tables and figures}

Figure A1: ACS vs. FL major effect estimates

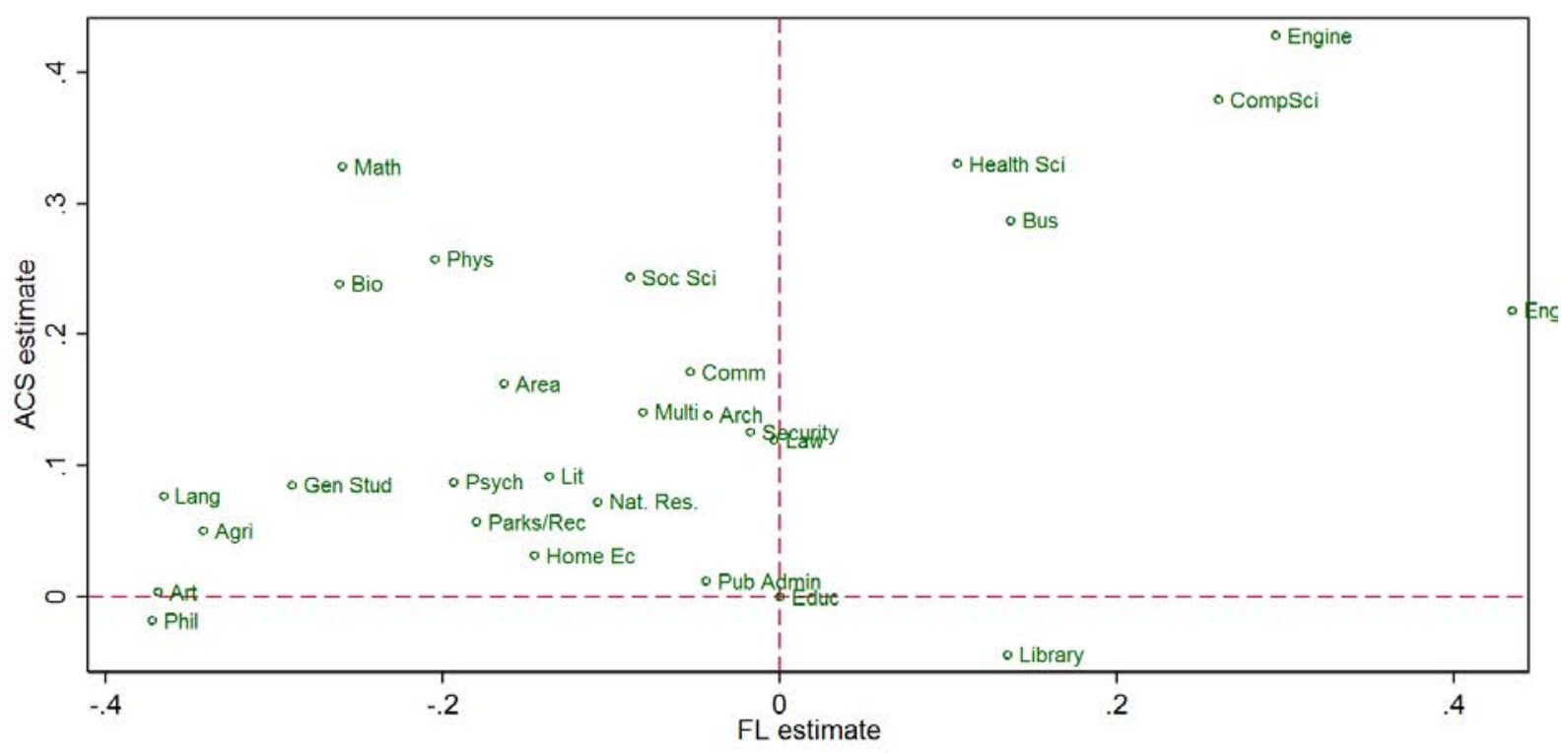

Estimated coefficients on for in ACS (vertical axis) versus FL (horizontal axis). Dependent variable is log earnings. ACS controls described in section 5.4. FL controls described in section 4.1. FL N=38,336. ACS N=1,272,597. Degree weighted correlation between ACS and FL estimates is 0.678 . 
Figure A2: Earnings PDVs per instructional dollar using ACS earnings estimates

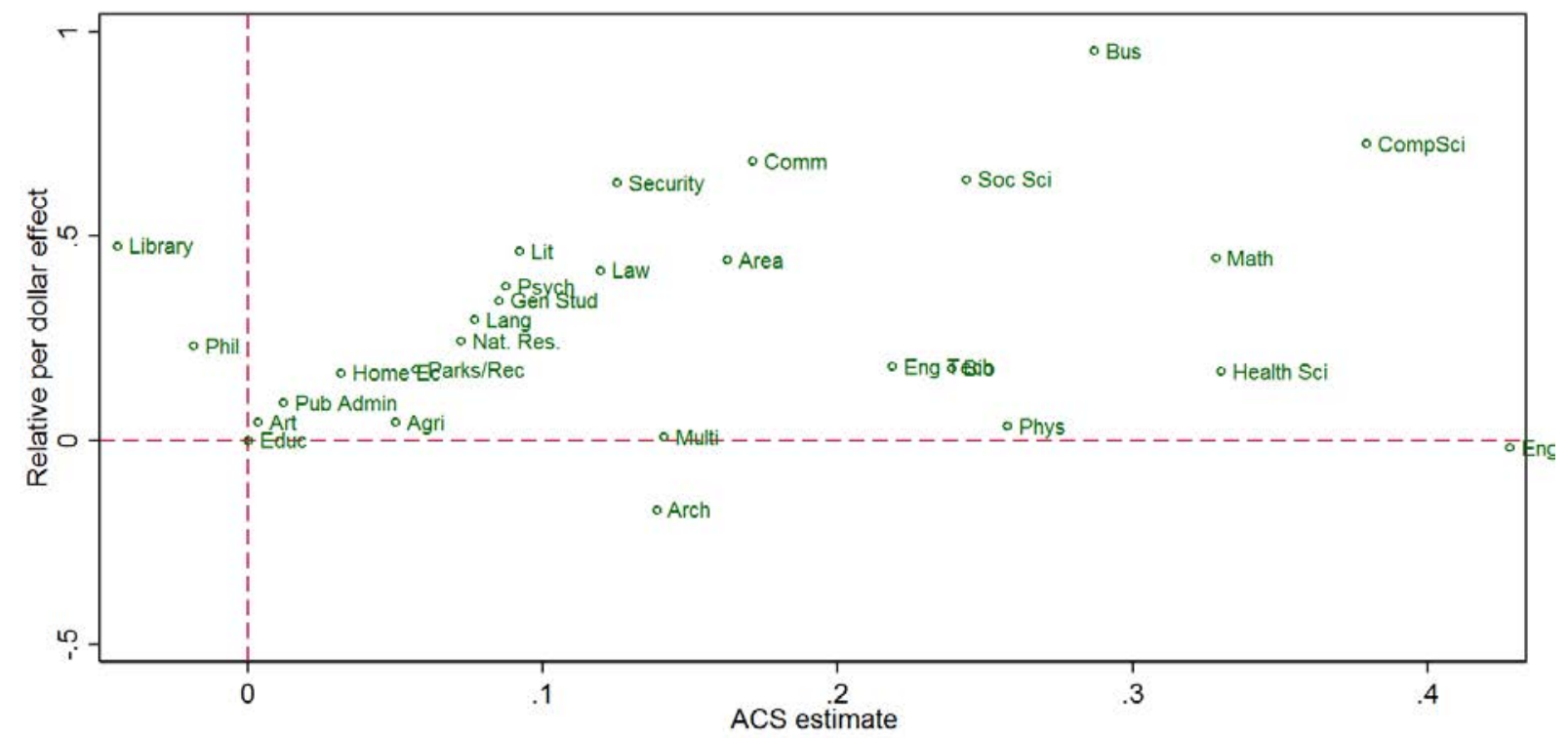

Horizontal axis: estimated log earnings effects from equation 6 in ACS data relative to omitted education category. Vertical axis: ratio of earnings to cost PDVs relative to ratio for reference education category, conditional on $X_{i}=x$, i.e.: $\frac{\operatorname{EARNPDV}_{j}(x) / \operatorname{COSTPDV}_{j}(x)}{\operatorname{EARNPDV} V_{\text {educ }}(x) / \operatorname{COSTPDV}_{\text {educ }}(x)}-1$. See section 5.5 for more details on per-dollar effect calculations. 
Table A1: Major classifications used in this paper

\begin{tabular}{lll} 
CIP code & Full name & Abbreviation \\
\hline 1 & agribusiness and agric production & Agri \\
3 & natural resources and conservation & Nat. Res. \\
4 & architecture and environmental design & Arch \\
5 & area and ethnic studies & Area \\
9 & communications & Comm \\
11 & computer and info sciences & CompSci \\
13 & education & Educ \\
14 & engineering & Engine \\
15 & engineering technologies & Eng Tech \\
16 & foreign languages & Lang \\
19 & home economics & Home Ec \\
22 & law & Law \\
23 & english lang literature ltrs & Lit \\
24 & liberal general studies & Gen Stud \\
25 & library and archival science & Library \\
26 & life sciences & Bio \\
27 & mathematics & Math \\
30 & multi interdisciplinary study & Multi \\
31 & parks rec leisure fitness studies & Parks/Rec \\
38 & philosophy and religion & Phil \\
40 & physical sciences & Phys \\
42 & psychology & Psych \\
43 & protective services & Security \\
44 & public administration and services & Pub Admin \\
45 & social sciences & Soc Sci \\
50 & visual arts & Art \\
51 & health sciences & Health Sci \\
52 & business and management & Bus \\
\hline
\end{tabular}


Table A2: Censoring by fields

Cens. Cens.

\begin{tabular}{lclc} 
Major & $\begin{array}{c}\text { Cens. } \\
\text { rate }\end{array}$ & Major & $\begin{array}{c}\text { Cens. } \\
\text { rate }\end{array}$ \\
\hline Fitness & 0.076 & Law & 0.081 \\
Math & 0.1 & Nat. Res. & 0.113 \\
Soc Sci. & 0.103 & Phys. Sci & 0.234 \\
Sec. & 0.076 & Educ. & 0 \\
Bus. & 0.054 & Pub. Admin & 0.069 \\
Psych. & 0.1 & Gen Stud. & 0.108 \\
Phil. & 0.226 & Lib Sci & 0.228 \\
Home Ec. & 0.103 & Art & 0.185 \\
Area Stud. & 0.185 & Arch & 0.115 \\
Comp Sci & 0.053 & Agri & 0.125 \\
Engl. & 0.088 & Eng. Tech & -0.01 \\
Comm & 0.1 & Health Sci & 0.035 \\
Lang & 0.171 & Inter. & 0.252 \\
Bio & 0.217 & Engine. & 0.127 \\
\hline
\end{tabular}

Estimates of regressions of the form given in equation 6 with a dummy variable for presence in earnings data as the outcome. Estimates expressed relative to omitted education category. Censoring rate in education programs is 0.128 . Estimates from regressions with $\mathrm{N}=38,336$. 